\title{
The influence of intraday seasonality on volatility transmission patterns
}

\author{
Nuria Alemany ${ }^{*}$, Vicent Aragó and Enrique Salvador ${ }^{* *}$ \\ Finance and Accounting Department, Universitat Jaume I,Castellon de la Plana, Spain
}

\begin{abstract}
Using data on a five-minute interval basis, this article analyses the effects of intraday seasonality on volatility transmission between the spot and futures markets of the CAC40, DAX30 and FTSE100. Remarkable differences in the impulse response analysis and in the dynamic and directional measurement of volatility spillovers are encountered depending on whether the intraday periodic component is considered. Thus, the convenience of removing intraday seasonality seems to be critical to reduce the risk of spurious causality when employing high-frequency data in volatility transmission. Moreover, the impact of market microstructure noise seems negligible when using an optimal frequency of observations.
\end{abstract}

Keywords: high-frequency data, intraday periodic component, Fourier Flexible Form, realized volatility, volatility spillover, microstructure noise

JEL Classification: G12, G13, G14, G15

\footnotetext{
${ }^{*}$ Corresponding author: Nuria Alemany, Finance and Accounting Department, Universitat Jaume I, Castellon de la Plana, Spain.Email: nalemany@uji.es

** The authors would like to thank Gonzalo Rubio, Maria Dolores Furió, Davide Avino, Thomas Conlon, the members of the Finance Department at University of Valencia and the participants at the XIX Conference on International Economics for helpful advice and suggestions. The authors acknowledge the financial support received from Universitat Jaume I of Castellón under the Research Personal Program PREDOC/2014/14 and the project UJIB2017-14 and the Spanish Ministry of Economy and Enterprise under project ECO2014/55221-P.
} 


\section{Introduction}

The transformation of the major stock exchanges into electronic financial markets has boosted the use of intraday data in different fields. Certainly, the recent availability of high-frequency data has offered more efficient ways for a more detailed analysis and further comprehension of market microstructure activity, both in the academic and financial world (Goodhart and O'Hara, 1997). This availability of high-frequency data can shed new light on issues concerning the volatility spillovers between markets that otherwise might be neglected when analysing data on a lower frequency basis. The importance of understanding volatility transmission comes from its crucial role in the pricing of many financial assets which is paramount in the overall decision-making process of investors, seeking to hedge risk, and policy makers, seeking to understand sources of contagion between markets. However, despite the proven benefits of using high-frequency data, there are two major issues that affect negatively its applications to volatility transmission studies, namely the market microstructure noise and the presence of intraday seasonality.

The presence of intraday seasonality seems to be one of the most problematic features when analysing volatility transmission on a high-frequency interval basis. The strong intraday repetitive pattern observed in the average absolute returns ${ }^{1}$ is a wellknown stylized fact of many financial markets. At market opening, absolute returns usually reach the highest values, and then around lunch hour, they decrease dramatically; finally, at the end of the trading day, they rise again. This suggests a U-

\footnotetext{
${ }^{1}$ Intraday volatility is often proxied by the average absolute returns.
} 
shaped seasonal volatility pattern ${ }^{2}$ (see, among others, Wood et al., 1985; Harris, 1986; Andersen and Bollerslev, 1997 and Tse, 1999). Due to this strong intraday periodicity detected in the average absolute returns, standard volatility models, which usually involve a monotone geometric decay in the autocorrelation structure of the absolute returns (for instance, standard $\mathrm{ARCH}$ models), are not appropriate and usually lead to spurious inference about the dynamics of the return volatility ${ }^{3}$ (Andersen and Bollerslev, 1997). Hence, the importance of considering the strong intraday seasonality exhibited by the data. The approach of Gallant $(1981,1982)$, based on the Fourier Flexible Form (FFF), has been proven particularly convenient to overcome the problem of seasonality detected in the intraday data and makes it possible to obtain deseasonalized or standardized data (Andersen and Bollerslev, 1997).

Also, a large volume of literature advocates that the Realized Volatility (RV), computed as the sum of the squared intraday returns for the given trading day, would be an excellent estimate of the volatility in an ideal world in which prices were observed continuously and without measurement error (Merton, 1980). Nonetheless, the presence of market microstructure noise in intraday data makes the estimation of volatility difficult because it induces autocorrelation in the intraday returns (Hansen and Lunde, 2006; Barndorff-Nielsen et al., 2011). On the other hand, some studies suggest that, to address the market microstructure noise, an appropriate return frequency is more relevant than the bias correction techniques. In this sense, some studies find that 'the

\footnotetext{
${ }^{2}$ Some markets exhibit a double U-shape pattern, one in the morning and the other one in the afternoon (Andersen et al., 2000; Harju and Hussain, 2011).

${ }^{3}$ Inference procedures implemented using high-frequency returns should consider, as noted by Andersen (2000),'The strong daily periodicity and the long run slow decay in the serial dependence'.
} 
five-minute horizon is short enough that the accuracy of the continuous record of asymptotics underlying our realized volatility measures work well, and long enough that the confounding influences from market microstructure frictions are not overwhelming' (Andersen, 2000) .

The main goal of this research lies in the importance of considering intraday seasonality to diminish the risk of spurious causality when using high-frequency data. We uncover that this seasonal component of volatility has a tremendous impact on the results and the conclusions reached in the studies about volatility transmission between spot and futures stock indexes. We contribute first by showing that volatility transmission differs significantly whether this seasonal pattern is considered or not. Cross-market volatility interactions between the spot and futures markets reduce substantially after considering the seasonal pattern revealing the perils of spurious causality if seasonality is neglected. Second, the response of spot and futures markets to unexpected shocks is lower when intraday seasonality is adjusted. The persistence of shocks in volatility reduces from very long spans (over 100 days) to relatively short periods of time (around two weeks). Third, we find that after considering the intraday seasonal component, the spot market is the largest net sender of volatility spillovers and, in terms of magnitude, the net volatility spillovers are generally greater in models in which seasonality has been removed. In this regard, if volatility is understood as a measure of information flow (Ross, 1989), it can be accepted that the main source of

\footnotetext{
${ }^{4}$ Based on the aforementioned idea that a suitable return frequency is more important than the bias correction methodology, we rely on observations on a five-minute interval basis to do the analysis without handling the market microstructure noise. Additionally, as robustness checks of our findings, we also analyze the extent to which market microstructure noise affects results.
} 
information emanates from the spot market and it is spread into the futures market ${ }^{5}$. Fourth, the conclusions of HFD-based approaches that remove market microstructure noise are similar in terms of causality analysis, persistence of volatility shocks and markets acting as net transmitters or receivers of volatility which reinforce the idea of considering intraday seasonality in the study of volatility transmission patterns.

To conduct this research, the futures and spot markets of the CAC40, DAX30 and FTSE100 are studied considering the following issues: a) high-frequency data on a five-minute interval basis, b) the FFF as a methodology to deseasonalise returns, c) two different estimation methods of volatility: the non-parametric realized volatility (RV) and the parametric Realized GARCH (RGARCH) model, d) an analysis of the volatility spillover and the Impulse Response effects on volatility models and e) the methodology developed by Diebold and Yilmaz (2012) to provide information about how much the spot (futures) market contributes to volatility in the futures (spot) market in net terms. This novel approach is based on forecast error variance decompositions from vector autoregression models to measure which markets are the net contributors and the net receivers of volatility spillovers.

The remainder of this paper is organized into seven sections. After this introductory section, section 2 contains a review of the literature. Section 3 explains the methodology employed followed by section 4 which describes the data used. In section 5 we present the empirical results while we perform a series of robustness checks in section 6 . Finally, section 7 concludes by summarizing the main results.

\footnotetext{
${ }^{5}$ Ross (1989) proves that in an arbitrage free economy, changes in conditional variances are directly related to the rate at which information flows to the market. Following this idea, one method of analysing how information flows between two assets is by examining their volatility relationships.
} 


\section{Review of literature}

Most of the empirical literature analysing the dynamics of volatility spillovers has focused on transmission across international stock indexes. However, the literature related to volatility transmission between the stock market index future and its underlying market is less extensive ${ }^{6}$.

Studies regarding the volatility transmission between spot and futures stock indexes can be organized into two major groups depending on the frequency of the data: a) The first category of studies employs data on a daily basis (Koutmos and Tucker 1996; Meneu and Torró, 2003 among others), and b) the second group of studies are based on high-frequency data (Kawaller et al. 1990, Chan et al., 1991; Tse, 1999; Fung et al., 2005 among others). Studies such as Koutmos and Tucker (1996) conclude that volatility transmission is unidirectional from the futures market to its underlying market. Kawaller et al. (1990) and Abhyankar (1995) conclude that this relationship depends on the time interval considered and that the intraday volatility transmission runs from one direction to another, in both directions, or in neither direction, concluding that there is not a systematic pattern of futures volatility leading the index volatility or vice versa. Chan et al. (1991), Tse (1999), Meneu and Torró (2003), and Fung et al. (2005) find evidence that there exists a two-way volatility transmission between the cash and futures markets. Additionally, it should be noted that Meneu and Torró (2003) and Chan et al. (1991) extend the analysis of volatility transmission by using the Impulse Response Function (IRF henceforth) and find evidence that shocks take a very long time to vanish. Concretely, Meneu and Torró (2003) document that the effect of the shock vanishes in about 100 days. It is worth mentioning that, although the empirical evidence about volatility spillovers between spot and futures markets diverges across articles, and there are some studies that document unilateral volatility spillover from the futures market to the spot market or the other way round, the conclusions

\footnotetext{
${ }^{6}$ Soriano and Climent (2006) review the literature on volatility transmission and provide a broad vision of the state of the art on this topic.
} 
drawn from previous research have mostly been supportive of the presence of bidirectional volatility transmission.

Last decades have witnessed the development of ground-breaking methodologies considering high-frequency data. With regard to volatility of asset returns, several approaches have been proposed to get more accurate estimates of volatility, both parametric and non-parametric. Andersen and Bollerslev (1998) were the pioneers of those models that employ realized volatility measures. They demonstrate that the daily aggregate squared intraday returns, known as the realized variance, can be employed as a proxy of latent volatility. More recently, Hansen et al. (2012) and Hansen et al. (2014) have developed a new framework, the RGARCH model, integrating the flexibility of the GARCH methodology with the statistical accuracy of the use of high-frequency data. These authors find that, when it comes to the empirical fit, the RGARCH structure outperforms the standard GARCH models. However, given the challenges posed by intraday seasonality and microstructure noise when using highfrequency data, literature considering these effects on volatility transmission patterns is scarce. Note that the studies which use intraday data mentioned above neglect the intraday periodic component and do not analyze the effect of microstructure noise.

Kofman and Martens (1997) is one of the pioneering studies regarding the effect of seasonality in volatility transmission across international stock indexes. They examine the spillovers between two international indexes, the FTSE100 and S\&P500, during overlapping trading hours, using high-frequency observations on a one-minute interval basis from January 1993 to June 1993 (121 trading days in total). These authors estimate the seasonal patterns in volatility using the FFF specification and compute the cross-serial correlation for raw and standardized return and conclude that after the deseasonalization of returns, cross-serial correlations noticeably decrease, suggesting 
that 'these results are the net spill-overs at the intraday level'.

Likewise, Martens et al. (2002) test whether filtering out the seasonal pattern improves the out-of-sample performance of volatility models and determine the best methodology to remove seasonality. They use thirty-minute observations for the spot exchange rates of the Deutsche mark and the Japanese yen against the U.S. dollar for the year 1996. The results suggest that the FFF is an efficient way of determining the seasonal component and that modelling the seasonal component improves forecasting performance. Thus, their approach helps to solve the problem of selecting the best alternative to model seasonal volatility from a wide variety of options available.

Wu et al. (2005) also examine the volatility transmission between the FTSE100 and S\&P500 indexes for the entire year of 1995 utilizing five-minute returns and they rely on the FFF to remove the effect of intra-daily periodicity. After removing the intraday patterns, significant bidirectional volatility spillovers are encountered.

Notice that these studies focus on international markets, use datasets that range from 6 months to 1 year and implement methodologies which are not based on realized measures. Neither do they expand the scope of the impact of intraday seasonality by including the impulse response and the net directional spillover effects in their analysis.

Another important issue, which have received a great deal of attention, is the impact of microstructure noise on the RV estimator. Some studies show that the realized variance may be sensitive to market frictions when applied to returns on a one-minute or less interval basis. These practical complications arise from issues such as price discreteness, bid-ask spreads or non-synchronous trades/quotes which complicates the application of realised estimators. It was Zhou (1996) who first introduced an adjustment to address market microstructure noise in high-frequency data using a 
kernel-based estimator. Notwithstanding, subsequent studies find that this estimator is not consistent when sample frequency increases and time interval is fixed. Since then, there has been an ongoing debate and excellent work on techniques dealing with market frictions. Barndorff-Nielsen et al. $(2008,2011)$ show how to design these estimators to guarantee robustness to certain types of frictions and efficiency using pre-filtering and kernel-methods ${ }^{7}$. Bandi and Russell (2006) develop an 'optimal' sample scheme where the frequency that maximises the signal-to-noise ratio is estimated. Zhang et al. (2005) propose a subsampling method to estimate the integrated variance consistently in the presence of microstructure noise by partioning the full grid of observations into $K$ nonoverlapping subgrids. On the other hand, there is a strand of literature that suggests that the RV has good properties when the frequency of observations considers a fixedinterval of five minutes, suggesting that by using this optimal frequency the impact of microstructure noise is not overwhelming (see among others, Andersen, 2000; Andersen et al., 2001; Pooter et al., 2008).

Given the limited research on volatility transmission that analyses the impact of the intraday seasonality of asset return volatility, we begin in the next section by explaining the FFF methodology to remove intraday seasonality. Next, the volatility models based on high-frequency data employed in this study are presented, namely the RV and the RGARCH models.

\footnotetext{
${ }^{7}$ For those readers interested in a comprehensive and detailed explanation about the kernel estimator see Barndorff-Nielsen et al. (2011).
} 


\section{Methodology}

\subsection{Fourier flexible form for deseasonalized volatility}

The intraday pattern in the volatility of financial market returns has an important impact on volatility modelling of high-frequency data. Two straightforward methods that consider the intraday pattern are as follows: a) a time-of-day volatility dummy is used for each return observation, or b) alternatively, the returns might be mean adjusted. Unfortunately, the first approach is generally over parameterized and leads to inefficient estimations and the second one is useless because the mean return is nearly zero (Andersen and Bollerslev, 1997; Andersen, 2000).

As Andersen and Bollerslev (1997) highlight, the FFF is especially convenient to deal with this intraday seasonality. This approach involves methods using linear polynomials regression and also Fourier methods, which consider sines and cosines to approximate the intraday periodic component.

The general framework for modelling high-frequency return volatility explicitly incorporates the effect of intraday periodicity. Concretely, the following decomposition for the intraday returns is considered:

$$
R_{t, n}=E\left(R_{t, n}\right)+\frac{\sigma_{t} S_{t, n} Z_{t, n}}{N^{1 / 2}}
$$

where $R_{t, n}$ represents the $n t h$ intraday return of day $t, E\left(R_{t, n}\right)$ indicates the unconditional mean, $N$ indicates the number of return intervals per day, $S_{t, n}$ is the periodic component for the $n t h$ intraday interval, $\sigma_{t}$ is the conditional volatility factor for day $t$ and $Z_{t, n}$ is an i.i.d. mean zero, unit variance error term assumed to be 
independent of the daily volatility process. By taking squares on both sides and applying logarithmic transformations, it can be rewritten as

$$
\log \left(\left(R_{t, n}-E\left[R_{t, n}\right]\right)^{2}\right)=\log \left(\frac{\sigma_{t}^{2} s_{t, n}^{2} z_{t, n}^{2}}{N}\right)
$$

From equation (2), define

$$
X_{t, n} \equiv 2 \log \left[\operatorname{abs}\left(R_{t, n}-E\left(R_{t, n}\right)\right]-\log \sigma_{t}^{2}+\log N \equiv \log S_{t, n}^{2}+\log Z_{t, n}^{2}\right.
$$

The linear FFF regression modelling approach is then based on the ordinary least squares (OLS) regression of $X_{t, n} \equiv f\left(\theta ; \sigma_{t} ; n\right)+\varepsilon_{t, n}$, where the error term $\varepsilon_{t, n} \equiv$ $\log \left(Z_{t, n}^{2}\right)-E\left(\log Z_{t, n}^{2}\right)$ is i.i.d mean zero, and $f\left(\theta_{t} ; \sigma_{t} ; n\right)$ takes the following parameterized form:

$$
\begin{aligned}
& \log \left(S_{t, n}^{2}\right)=f\left(\theta ; \sigma_{t} ; n\right)=\sum_{j=0}^{J} \sigma_{t}^{j}\left[\mu_{0 j}+\mu_{1 j} \frac{n}{N_{1}}+\mu_{2 j} \frac{n^{2}}{N_{2}}+\sum_{i=1}^{D} \lambda_{i j} I_{n=d_{i}}+\right. \\
& \left.\sum_{p=1}^{P}\left(\gamma_{p j} \cos \frac{p n 2 \pi}{N}+\delta_{p j} \sin \frac{p n 2 \pi}{N}\right)\right]
\end{aligned}
$$

where $\theta \equiv\left(\mu_{0 j}, \ldots, \mu_{0 J}, \mu_{1 j}, \ldots, \mu_{1 J}, \mu_{2 j}, \ldots, \mu_{2 J}, \lambda_{i j}, \ldots, \lambda_{D J}, \gamma_{p j}, \ldots, \gamma_{P J}, \delta_{p j}, \ldots, \delta_{P J}\right)$ are unknown parameters to estimate, $N_{1}, N_{2}$ are normalizing constants defined as $N_{1}=$ $(N+1) / 2 ; \quad N_{2}=(N+1)(N+2) / 6$ and $I_{n=d_{i}}$ are dummy variables that capture irregularities $^{8}$ in the seasonal pattern. Additionally, if $\mathbf{J}>0$, the whole regression is multiplied by the daily volatility factor $\sigma_{t}^{j_{9}}$.

\footnotetext{
${ }^{8}$ The intervals corresponding to the opening of the US markets and the announcement of US macro news are the ones controlled by these dummies.
} 
Additionally, according to Berument and Kiymaz (2001), knowing the volatility pattern of stock index returns by day of the week 'may allow investors to adjust their portfolios by taking into account day of the week variations in volatility'. Thus, to deepen the understanding of the seasonal volatility pattern and determine whether market volatility is the same or different for each day of the week, the intraday periodic component should be classified by weekday. Likewise, it is also convenient to include the well-documented expiration and maturity effects in the Fourier regression (for more details about the expiration and maturity effect see among others: Samuelson, 1965; Stoll and Whaley, 1987; Hancock, 1993; Karolyi, 1996; Chow et al., 2003; Duong and Kalev, 2008) $)^{10}$

Hence, after including these three effects (DOW, expiration and maturity), by using dummy variables, the Fourier regression is expressed as follows:

$$
\begin{aligned}
& \log \left(S_{t, n}^{2}\right)=f\left(\theta ; \sigma_{t} ; n\right)=\sum_{j=0}^{J} \sigma_{t}^{j}\left[\mu_{0 j}+\mu_{1 j} \frac{n}{N_{1}}+\mu_{2 j} \frac{n^{2}}{N_{2}}+\right. \\
& \sum_{i=1}^{D} \lambda_{i j} I_{n=d_{i}}+\sum_{s} \tau_{s} D_{s}+\sum_{x} \eta_{x} D_{x}+\sum_{p=1}^{P}\left(\gamma_{p j} \cos \frac{p n 2 \pi}{N}+\right. \\
& \left.\left.\delta_{p j} \sin \frac{p n 2 \pi}{N}\right)\right]
\end{aligned}
$$

\footnotetext{
${ }^{9}$ We employ the widely used parametric GARCH $(1,1)$ model to capture daily volatility. In most empirical applications, the $\operatorname{GARCH}(1,1)$ is enough to reproduce the volatility dynamics of financial series, and thus the GARCH $(1,1)$ is the 'workhorse' model for both academics and practitioners (Engle, 2001).

${ }^{10}$ To our knowledge, this is the first study to examine the day of the week (DOW) effect and the expiration and maturity effects on volatility by means of the FFF.
} 
where variables $D_{s}$ represent dummy variables for each day of the week. Their role is to capture the daily effects by taking a value of 1 at each five-minute interval belonging to a trading day of the week (s=Monday, Tuesday, Wednesday, Thursday and Friday) and 0 otherwise. Variables $D_{x}$ are dummy variables for each expiration and maturity date. These dummy variables capture the expiration and maturity effects by taking the value 1 at each five-minute interval belonging to a trading day of the expiration week and 0 otherwise $^{11}$. Additionally, $\tau_{s}$ and $\eta_{x}$ are also unknown parameters accompanying these variables.

In order to implement the Fourier regression, a two step procedure is applied: In the first stage, $\hat{X}_{t, n}$ is computed from equation (3). Then, $\hat{X}_{t, n}$ is considered as a dependent variable in the Fourier regression (5), which is estimated by OLS.

Once $\widehat{f}\left(\hat{\theta} ; \sigma_{t} ; n\right)$ is calculated, the intraday periodic component $\hat{S}_{t, n}$ for interval $n$ on day $t$, which provides a close approximation to the overall volatility patterns in each market, is retrieved as:

$$
\hat{S}_{t, n}=\frac{T \cdot e\left(\hat{f}_{t, n} / 2\right)}{\sum_{t=1}^{\left[\frac{T}{N}\right]} \sum_{n=1}^{N} e\left(\hat{f}_{t, n} / 2\right)}
$$

Finally, the standardized five-minute returns series are defined as follows:

$$
\hat{R}_{t, n} \equiv R_{t, n} /\left(\widehat{\sigma}_{t} \hat{S}_{t, n}\right)
$$

\footnotetext{
${ }^{11}$ Additionally, the day before expiration and the week before expiration have also been considered in our analysis. The results are available upon request.
} 


\subsection{Volatility models}

In this study we implement two techniques to obtain volatility estimates that consider different volatility concepts, measurement and modeling procedures. The reason to do this is to show that our results are not driven by the choice of a particular volatility estimator but that hold for different specifications. The first one, the realized volatility, is a non-parametric estimator free from any functional form assumption which affords estimates of volatility that are flexible yet consistent. The second one, the Realized GARCH model, is a parametric procedure that relies on explicit functional form assumptions regarding the expected volatility. In this case of discrete time ARCH class of models, the expectations are formulated in terms of directly observable variables. We provide in this subsection a succinct overview of the RV theory ${ }^{12}$ and the novel RGARCH methodology ${ }^{13}$.

\subsubsection{Realized Volatility}

Consider a simple discrete time model in which the daily returns of a given asset are typically characterized as follows,

$$
R_{t}=h_{t}^{1 / 2} \eta_{t}
$$

where $\left\{\eta_{t}\right\}_{t=1}^{T}$ is a sequence of independently and normally distributed random variables with zero mean and unit variance, $\eta_{t} \sim \operatorname{NID}(0,1)$.

\footnotetext{
${ }^{12}$ For further details see Andersen and Bollerslev, 1998; Andersen et al. 2001, 2003; BarndorffNielsen and Shephard, 2002;McAleer and Medeiros, 2008.

${ }^{13}$ A more extensive theoretical explanation can be found in Hansen et al. 2012, 2014.
} 
Assume that, in a given trading day $t$, the logarithmic prices are observed tick by tick. Consider a grid $\Lambda_{t}=\left\{\tau_{0}, \ldots, \tau_{n_{t}}\right\}$ containing all observation points, and set $p_{t, n}, n=1, \ldots, n_{t}$ to be the $n t h$ price observation during day $t$, where $n_{t}$ is the total number of observations at day $t$.

Moreover, hypothesize that

$$
R_{t, n}=h_{t, n}^{1 / 2} \eta_{t, n}
$$

where $\eta_{t, n} \sim \operatorname{NID}\left(0, n_{t}^{-1}\right), R_{t, n}=p_{t, n}-p_{t, n-1}$ is the $n t h$ intraperiod return of day $t$ so that

$$
R_{t}=\sum_{n=0}^{n_{t}} R_{t, n}
$$

and

$$
h_{t}=\frac{1}{n_{t}} \sum_{n=1}^{n_{t}} h_{t, n}
$$

Describe the information set $\hat{S}_{t, n} \equiv \tilde{S}\left\{p_{a, b}\right\}_{a=-\infty, b=0}^{a=t, b=n}$ as the $\sigma$-algebra generated by all the information to the $n t h$ tick in day $t$. Therefore, $\hat{S}_{t, 0}$ is the information set available before the start of day $t$. Then, it follows that $E\left(R_{t}^{2} \mid \hat{S}_{t, 0}\right)=h_{t}$ and $\mathrm{V}\left(R_{t}^{2} \mid \hat{S}_{t, 0}\right)=2 h_{t}^{2}$

The realized variance, defined as the sum of all available intraday highfrequency squared returns given by 


$$
R V_{t}^{(a l l)}=\sum_{n=0}^{n_{t}} R_{t, n}^{2}
$$

is a consistent estimator of the integrated variance when there is no microstructure noise (Andersen et al. 2003).

\subsubsection{Realized GARCH}

Hansen et al. $(2012,2014)$ introduce a new approach, RGARCH, for the joint modeling of a GARCH structure for returns and realized measures of volatility, filling the gap between two lines of research in volatility modeling: high-frequency data and GARCH models. In the GARCH $(1,1)$ model the conditional variance $h_{t}$ is a function of $h_{t-1}$ and $\mathrm{R}_{\mathrm{t}-1}^{2}$. In this approach, $\mathrm{h}_{\mathrm{t}}$ will be a function of $\mathrm{x}_{\mathrm{t}-1}$ as well, which represents a realized measure of volatility, such as the realized variance. The general structure of the RGARCH (p, q) model is as follows:

$$
\begin{aligned}
& R_{t}=\sqrt{h_{t} z_{t}} \\
& h_{t}=v\left(h_{t-1}, \ldots, h_{t-p}, x_{t-1}, \ldots, x_{t-q}\right) \\
& x_{t}=m\left(h_{t}, z_{t}, u_{t}\right)
\end{aligned}
$$

where $z_{t} \sim$ i.i,d $(0,1)$ and $u_{t} \sim$ i.i.d. $\left(0, \sigma_{u}^{2}\right)$ with $z_{t}$ and $u_{t}$ being mutually independent.

The key variable in this model is the conditional variance, $h_{t}=\operatorname{var}\left(R_{t} \mid F_{t-1}\right)$, where $R_{t}$ is a time series of returns and $F_{t}=\sigma\left(R_{t}, x_{t}, R_{t-1}, x_{t-1}, \ldots\right)$ 
Equations (13), (14) and (15) are defined as return, GARCH and measurement equation respectively.

\section{Data: Descriptive statistic for raw and standardized data}

\subsection{Datasets}

Our empirical data set comprises high-frequency observations on a five-minute interval basis of transaction prices from different markets, namely, CAC40, DAX30 and FTSE100, for both the stock index and the index futures during the period from the $1^{\text {st }}$ July 2003 to the $30^{\text {th }}$ September, 2015. Only data for the period of simultaneous operation of the spot market and future market are used in this study.

The continuously compounded returns are computed at each five-minute interval by taking the logarithms and subtracting the previous value. So, the five-minute raw returns $R_{t, n}$ at the $n-t h$ interval at day $t$ for $n=1,2 \ldots N$ and $t=1,2, \ldots T$ are computed as follows:

$$
R_{t, n}=100 \times \log \left(\frac{P_{t, n}}{P_{t, n-1}}\right)
$$

where $P_{t, n}$ represents the spot $\left(S_{t, n}\right)$ and future $\left(F_{t, n}\right)$ price level on interval $n$ at day $t$.

Table 1 reports some summary statistics for raw returns $R_{t, n}$ on a five-minute interval basis. Average returns for all markets are close to zero. Returns are characterized by statistically significant kurtosis, suggesting that the series are leptokurtic; that is to say, the series have fatter tails and higher peaks compared with a 
normal distribution. Also note that the Jarque-Bera test suggests that the returns are far from being normal.

In order not to mislead the statistical inference, the first return of the trading day, 09:05 hour, which generally reflects the adjustment to overnight information and is regarded as the highest average return variability, is removed (Andersen et al., 2000). ${ }^{14}$

\section{[INSERT TABLE 1]}

Additionally, the bottom part of Table 1 displays the first order autocorrelation coefficient AC (1). As can be appreciated, it is small for returns for the three markets analysed. Nonetheless, it increases considerably for absolute raw returns (which stand at approximately 0.3 as shown in Table 1 ), suggesting volatility persistence.

\subsection{Deseasonalization}

As underlined by Andersen and Bollerslev (1997), an appropriate intraday dynamic analysis requires computing and extracting the intraday periodic component of return volatility. Thus, following these authors and in view of the $\mathrm{AC}$ (1) results for absolute raw returns, the next step is to evaluate whether there are intraday patterns in our data. To do so, the intraday average absolute returns for each five-minute interval are depicted in Figure 1. Whereas it is notable that the intraday average returns are centred on zero with little clear evidence for any systematic pattern ${ }^{15}$, Figure 1 reveals that the volatility dynamic of high-frequency spot and future returns, often estimated as the

\footnotetext{
${ }^{14}$ This leaves us with a sample of 3,055 trading days for CAC40, 3,070 trading days for DAX30 and 2,982 days for FTSE100, each day consisting of 101 intraday returns.

${ }^{15}$ To keep this article to a reasonable length the intraday average returns plot is not attached to this document. It is available upon request.
} 
average of the absolute returns during a time interval, is characterized by remarkable intraday patterns.

\section{[INSERT FIGURE 1]}

A widely known stylized fact about the intraday statistical features of many financial markets is that volatility is higher at the opening and closing of the trading day and lower in the middle (see, among others, Wood et al. 1985, Harris 1986, Tse 1999). This strong intraday periodicity in the average absolute returns is hereby confirmed by Figure 1. However, they do not present the conventional intraday U-pattern; instead, they suggest a distorted double U-shape pattern in the sample autocorrelations, which occupies precisely one day. All markets show a decaying pattern in intraday volatility until 14:30 (which corresponds to the interval 65 in Figure 1). At 14:35 (interval 66), return volatility increases considerably and then declines until 15:30 (interval 77), a point at which a remarkable increment occurs again and remains relatively high until 17:30, reaching its maximum peak at 16:05 (interval 84$)^{16}$. This pattern is similar to that found by Harju and Hussain (2011) for the major European equity markets, that is to say, CAC40, FTSE100, SMI and DAX 30 indexes, from 1 September 2000 to 31 March 2006. They identify a periodic pattern in the intraday volatilities that resembles a $\mathrm{W}$, and find evidence that US macroeconomic announcements ${ }^{17}$ at 14:30 and 16:05, and the NYSE cash market opening time at 15:30 have cross border impacts on European equity volatilities.

After corroborating evidence of intraday periodicities in return volatility and the noticeable repetitive pattern in the 10-day autocorrelogram for the absolute returns, we

\footnotetext{
${ }^{16}$ For the FTSE100 index this pattern occurs an hour earlier due to the different time zones.

${ }^{17}$ Such as, Producer Price Index, Retail Sales, Consumer Price Index, Consumer Confidence, etc.
} 
implement the FFF to compute the intraday periodic component, $\hat{S}_{t, n}$ by means of equations (5) and (6).

In our empirical application, we follow Andersen and Bollerslev (1997) and set $\mathrm{J}=1$, allowing the pattern to be a function of the daily volatility factor and the optimal value of the coefficient $\mathrm{P}$ is determined by means of Schwartz Information Criteria or Akaike information Criteria. Moreover, dummy variables have been considered for the five-minute interval in which volatility rises dramatically (see Figure 1$)^{18}$

Regarding the DOW effect (represented by $D_{s}$ in equation in equation (5)), literature states that market participants behave in a different way depending on the day of the week. Consistent with the previous literature, results corroborate that there exists a DOW effect on market volatility for the three markets analysed for both the spot and the future stock index. Moreover, the highest volatility is observed on Thursday and Friday, whereas the lowest volatility occurs on Monday (see, among others, Han et. al, 1999; Kiymaz and Berument, 2003).

As far as the maturity effect is concerned (variable $D_{x}$ in equation (5)), according to the Samuelson (1965) hypothesis, futures prices should increase as the futures contract approaches the expiration date. However, there is a wide range of literature that documents that the maturity effect in financial futures is weaker (Duong and Kalev 2008). Related to the expiration effect, some studies suggest that stock market volatility tends to increase significantly when the expiration date of the futures

\footnotetext{
${ }^{18}$ Concretely, volatility is remarkably higher at intervals 14:35-14:40 and 16:05 for CAC40 and DAX30, and at intervals 13:35-13:40 and 15:05-15:10 for FTSE (keep in mind that for the FTSE100 this pattern occurs an hour earlier due to different time zones).
} 
contracts approach (see, among others, Stoll and Whaley 1991). Nevertheless, there are those that find the opposite results (Kan 2001). Thus, the effect of the expiration of futures contracts on spot market volatility, the so called expiration effect, is far from conclusive (Stoll and Whaley 1987, 1991, Hancock 1993, Karolyi 1996,Chow et al. 2003, among others). Our results suggest that there is a significant increase in the conditional variance of the stock index and the stock index future in the week of the expiration day for the three markets analysed ${ }^{19}$.

After having estimated the intraday periodic component, standardized fiveminute returns are computed using equation (7).

\section{[INSERT FIGURE 2]}

Figure 2 depicts the autocorrelogram for the absolute returns (the dashed line) and absolute standardized returns (the solid line) considering a maximum lag length of 10 trading days. The periodic volatility pattern across each trading day, whose origin is the intraday seasonality illustrated in Figure 1, is clearly illustrated by the autocorrelation structure of absolute returns, and it reveals the importance of considering the intraday seasonal component of the volatility and the hazard of straightforward ARCH modelling of intraday return volatility (Andersen and Bollerslev 1997). As can be appreciated in Figure 2, after standardizing the data, the periodic dependencies have been considerably reduced, and there is a significant decay in the serial autocorrelation. From observation 600-700 (approximately 1 week) onwards,

\footnotetext{
${ }^{19}$ To keep this article to a reasonable length, results are not attached to this article, but they are available upon request.
} 
autocorrelation is close to zero for the spot and futures market and for the three indexes surveyed (see the solid line in Figures 2.1, 2.2 and 2.3).

To provide a measurement of the reduction in the periodic dependencies, the AC (1) coefficient for absolute standardized returns is calculated as well (see at the bottom side of Table 1 that the $\mathrm{AC}(1)$ coefficient is 0.3 approximately for absolute raw returns, whereas it is around 0.1 for absolute standardized returns). Therefore, it can be inferred that the FFF significantly reduces the intraday seasonality. Furthermore, to comprehensively understand financial market performance and model volatility dynamics, the analysis of cross-serial correlations between assets is highly relevant. Previous research has documented significant cross-serial correlations between spot and futures market returns (see, among others, Kawaller et al., 1987, Herbst et al., 1987, Brooks et al., 1999). At this stage, it is important to analyse the differences in the degree of cross-serial correlation between spot and futures markets considering both raw and standardized returns in a similar way to the analysis implemented in Figure 2. Thus, consider now the five-minute intraday absolute returns (dashed line) and the five-minute intraday absolute standardized returns (solid line) cross-serial correlations between the spot and futures markets up to ten days depicted in Figure 3.

\section{[INSERT FIGURE 3]}

Note that the dashed line reveals a similar pattern detected in the 10-day autocorrelogram for the absolute returns (see Figure 2), suggesting the presence of significant cross-market volatility interactions between the spot and futures market. All markets show a U-pattern correlogram each trading day. Cross-serial correlations increase at the beginning of the day $(0.30$ for CAC40, 0.31 for DAX30 and 0.33 for FTSE100), then decline until 12:15 approximately (0.12 for CAC40, and DAX30 and 0.15 for FTSE100), the point at which an increment occurs again and remains relatively 
high until 17:30. As we expected after standardizing the returns, it can be appreciated in Figure 3 (solid line) that cross-serial correlations for standardized absolute returns have been steadily reduced and remain relatively constant during the trading day ( 0.02 for the three indexes). This finding is consistent with results obtained by Kofman and Martens (1997) and underscores, once more, the importance of considering seasonalities present in high-frequency data. Otherwise, significant bias in the second moment causality analysis might be introduced.

The conclusions reached in this section highlight significant differences, particularly a noticeable reduction in correlation, either in the autocorrelation or in the cross-serial correlation when considering raw or standardized data. These findings lead us to conjecture that remarkable differences might be encountered in the results of studies regarding volatility spillover and certainly in the response to a shock on volatility through the IRF.

Thus, in the next section, the focus of attention is on analysing the results obtained through models in which raw data are considered (that is to say, those that do not remove the seasonal or periodic component) with results reached by models with standardized data. To this end, we implement the RV and RGARCH methodologies considering raw and standardized data. Additionally, the impact of microstructure noise will be addressed in a final robustness section. 


\section{Empirical results: Volatility transmission, impulse response function and directional measurement of volatility spillovers.}

Based on the results reached so far, in section 5.1, we investigate the daily volatility transmission by using the bivariate vector autoregressive model (VAR) and the consequences of the presence of seasonality in the volatility spillover analysis when using high-frequency data. Additionally, in section 5.2, an impulse response analysis is implemented to deepen the understanding of volatility transmission. Finally, in section 5.3, we use the spillover index approach proposed by Diebold and Yilmaz (2012) to measure the net pairwise volatility spillovers among the spot and futures markets of the CAC40, DAX30 and FTSE100 indexes.

\subsection{Volatility transmission}

Ross (1989) suggests that the volatility of an asset is directly related to the rate of information flow in a market. Because information flow is the core of risk management and asset pricing, it is crucial to fully understand volatility dynamics and the way in which volatility is transmitted across markets. Vector autoregressive (VAR) models have become one of the most widely used methodologies in the fields of macroeconomics and financial economics to analyse the existence of volatility spillover effects between two markets. In this section, we use the following bivariate model to examine the way in which spot and futures markets interact through their second moments. 


$$
\begin{gathered}
V_{s, t}=\alpha_{s}+\sum_{i=1}^{k} \beta_{s s, i} V_{s, t-i}+\sum_{i=1}^{k} \beta_{s f, i} V_{f, t-i}+\varepsilon_{s, t} \\
V_{f, t}=\alpha_{f}+\sum_{i=1}^{k} \beta_{f s, i} V_{s, t-i}+\sum_{i=1}^{k} \beta_{f f, i} V_{f, t-i}+\varepsilon_{f, t} \\
\left(\begin{array}{c}
\varepsilon_{s, t} \\
\varepsilon_{f, t}
\end{array}\right) \sim N(0, \Sigma)
\end{gathered}
$$

where $\boldsymbol{V}_{\boldsymbol{s}, \boldsymbol{t}}, \boldsymbol{V}_{\boldsymbol{f}, \boldsymbol{t}}$ and $\boldsymbol{V}_{\boldsymbol{s}, \boldsymbol{t}-\boldsymbol{i}}, \boldsymbol{V}_{\boldsymbol{f}, \boldsymbol{t}-\boldsymbol{i}}$ are the contemporaneous spot and futures daily volatilities and the lagged spot and futures daily volatilities, respectively $\boldsymbol{\alpha}_{\boldsymbol{s}}$ and $\boldsymbol{\alpha}_{\boldsymbol{f}}$ represent the unconditional spot and future market daily volatilities; coefficients $\beta_{s s, i}, \beta_{s f, i}, \beta_{f s, i}, \beta_{f f, i}$ are the parameters accompanying the lagged daily volatilities and $\varepsilon_{s t}$ and $\varepsilon_{f t}$ are the residuals in the spot and futures volatility equations which are assumed to follow a normal distribution with mean equal to zero and variance $\Sigma$. Our focus is on the consequences of ignoring or considering the periodic intraday component on the study of volatility transmission. First, we analyse the effects on volatility transmission when the intraday seasonality is neglected. To do so, we perform a VAR estimation employing the following input data: daily realized volatilities computed using raw returns and the $\operatorname{RGARCH}(1,1)$ model (VAR A) and daily realized volatilities using raw returns and the RV method (VAR B). Then, the convenience of removing the seasonal component to reduce the risk of spurious causality in the analysis of volatility spillovers is evaluated by estimating the VAR model using daily realized volatilities computed with standardized returns and the RGARCH (VAR C) and daily realized volatilities using standardized returns and the RV method (VAR D). 


\section{[INSERT TABLE 2]}

Table 2 displays results from the estimations of the VAR A, VAR B, VAR C and the VAR D models ${ }^{20}$. Note that those models that do not consider intraday seasonality (VAR A and VAR B) include more lags than those that consider it (VAR C and VAR D). See for instance that, the VAR A model includes 6, 5 and 4 lags for the CAC40, DAX30 and FTSE1000 respectively, whereas the VAR C includes only 5 lags for the CAC40, 2 lags for the DAX30 and 3 lags for the FTSE100 index (see that for significant lags the pattern is the same, that is to say, the models with more significant lags are those that use raw data). The most likely explanation of this finding is that the repetitive pattern in the autocorrelogram for the absolute returns (dashed lines in Figure 2) makes some variables redundant in equation (16). Therefore, this outcome may be indicative of the presence of spurious causality in the VAR A and VAR B models.

Certainly, one of the best ways to fully understand how volatility shocks in one market affect the volatility of the other market is to invert the system in order to express volatilities as a function of all past shocks emanating from both markets, that is to say, by means of the IRF, which we implement in the next section.

\subsection{Impulse response function}

Since the seminal contribution by Sims (1980), the dynamic interaction between the variables and the disturbances in vector autoregressive models (VARs) has been widely analysed using the impulse response methodology. The IRF is considered to be a useful mechanism to study the effect of a shock on the variables in the model throughout time

\footnotetext{
${ }^{20}$ The optimal lag length for each bivariate VAR model has been set by means of the AIC/BIC criteria.
} 
and can be generalized to the study of shocks in volatility ${ }^{21}$. The IRF will therefore provide valuable information about the impact of a shock on volatility.

Figures, 4, 5 and 6 exhibit the IRFs for an unexpected shock for the CAC40, DAX30 and FTSE100 indexes, respectively.

\section{[INSERT FIGURES 4 TO 6]}

As can be appreciated in Figures 4.1(CAC40), 5.1(DAX30) and 6.1(FTSE100), when daily volatilities are computed by means of the RGARCH model using raw returns (named VAR A), after the shock hits the system, volatility increases ${ }^{22}$ between $1.4 \times 10^{-5}$ and $1.6 \times 10^{-5}$ and then steadily diminishes until the shock stabilizes after approximately 200 days in the three markets ${ }^{23}$. Thus, the results show that the degree of volatility persistence is remarkably higher when the intraday periodic component is not considered and the daily volatility is estimated through a RGARCH model. This result highlights that standard volatility models, which usually involve a monotone geometric decay in the autocorrelation structure of the absolute returns, may not be appropriate and might lead to spurious inference about the dynamic of the return volatility when strong intraday periodicity is observed in the average absolute returns (Andersen and Bollerslev 1997).

Likewise, note that in Figures 4.2 (CAC40), 5.2 (DAX30) and 6.2 (FTSE100), the magnitude of the shock when daily volatilities are computed using RV with raw

\footnotetext{
${ }^{21}$ The Generalized impulse response function by Pesaran and Shin (1998) is applied.

${ }^{22}$ It represents an 11 percentage increase in volatility approximately.

${ }^{23}$ Meneu and Torró (2003) study the volatility transmission between the IBEX 35 Index and IBEX 35 Futures Index using daily data and extend their analysis implementing an impulse response analysis. They find evidence that shocks take a very long time to vanish (about 100 days).
} 
returns (named VAR B) is significantly greater (approximately $1.2 \times 10^{-4}$ for the CAC40, $1.4 \times 10^{-4}$ for the DAX30, and $1.8 \times 10^{-4}$ for the FTSE100 indexes ${ }^{24}$ ) and exhibits a rather erratic pattern during the first days after the shock. Furthermore, observe that the effect of the shock is less persistent and disappears in about 90 days for the CAC40 and DAX30 indexes and after 25 days for the FTSE100 index. Notice that, models VAR A and B ignore the presence of market seasonality in high-frequency data. This fact may hamper the estimation of volatility because it induces autocorrelation in the intraday returns; and, as a consequence of this, the results obtained through these two models might be questionable. Thus, we take a step forward to analyse how the outcome changes after removing seasonality.

Strikingly, as can be noted in Figures 4.3 (CAC40), 5.3 (DAX30) and 6.3 (FTSE100), when the intraday periodic component has been removed before conducting volatility transmission analysis, using volatilities estimated with the RGARCH models with standardized returns (VAR C model), the effect of the shock vanishes after approximately 19-21 days in the three markets. In terms of magnitude, volatility increases by around $1.1 \times 10^{-5}$ for the CAC40, $0.9 \times 10^{-5}$ for the DAX30 Index and approximately $0.7 \times 10^{-5}$ for FTSE100 after the shock hits the system ${ }^{25}$. Note that when a shock is applied to one market the immediate market responses are pronounced, and then, the impact of the shock declines until the effect dies out after about 20 days in the three indexes. Note that the impact evolves in a similar pattern regardless of the market in which the shock takes place. Observe for instance that for the CAC40 index, after a

\footnotetext{
${ }^{24}$ The percentage increase in volatility is about 80,60 and 200 for CAC40, DAX30 and FTSE indexes respectively.

${ }^{25}$ Volatility increases about 10, 9 and 7 percent for CAC40,DAX30 and FTSE100 indexes respectively, after a shock hits the system.
} 
shock on the spot (futures) market, volatility in any market rises approximately $1 \times 10^{-5}$ and then, it declines until the effect of the shock dies out after about three weeks.

Results obtained using the RV model and standardized returns (VAR D model) are similar to those findings achieved in the previous VAR (VAR C model), in the sense that, compared with those VAR models that neglect the intraday periodic component, persistence is dramatically reduced when intraday seasonality is considered. See in Figures 4.4, 5.4 and 6.4 that after approximately 7 days the effect of a shock completely disappears. As far as the size of the shock is concerned, results suggest once more, that when using RV models the magnitude of the shock is greater than when using the RGARCH models (similar to findings in the previous VAR B model, and it comes from the nature of the RV and RGARCH models) ${ }^{26}$.

Consequently, the most remarkable results of this section may be summarised as follows: a) Volatility transmission differs significantly whether raw and standardized returns are considered or not, suggesting that if the seasonal pattern is neglected, it might have serious side effects in the spillover analysis, b) when a shock hits the system and the intraday periodic component has not been used to adjust the returns before conducting the spillover analysis, the response to that shock is highly persistent; and c) the results obtained in the impulse response analysis are consistent with previous findings (Chan et al. 1991, Meneu and Torró 2003) and suggest that there exists bidirectional interaction between the stock index and the stock index future, although we find evidence that shocks on volatility are far less persistent.

\footnotetext{
${ }^{26}$ When a shock hits the system, volatility increases 70,60 and 90 percentage points for CAC40, DAX30 and FTSE100 indexes respectively.
} 
One limitation of the IRF is that is not very helpful to analyse the direction of the transmission of volatility. To further assess spillovers across spot and futures markets, the Diebold and Yilmaz (2012) Spillover Index is implemented in the following section.

\subsection{Directional measurement of volatility spillovers}

Diebold and Yilmaz (2012) show how it is possible to aggregate spillover effects across markets, capturing a great deal of information in a single spillover measure. This volatility spillover measure is based on forecast error variance decompositions from vector autoregressions and it is useful for measuring the impact that shocks on a market have on the volatility of others markets. This method, which is an extension of the one proposed in Diebold and Yilmaz (2009), has two main advantages: a) The generalized variance decomposition makes spillover measures independent of the ordering of variables in the VAR model, and b) not only does it consider the total spillovers from one market to another, but it also considers the directional and the net spillovers ${ }^{27}$.

This section is devoted to the study of the net directional spillover effects among the spot and futures markets utilizing the novel Diebold and Yilmaz (2012) approach mentioned above ${ }^{28}$. Our main focus is the net pairwise volatility spillover (NPVS)

\footnotetext{
${ }^{27}$ For more details about this methodology, see Diebold and Yilmaz $(2009,2012)$.
}

${ }^{28}$ We follow Diebold and Yilmaz (2012) and use generalized variance decompositions of 10day ahead volatility forecast errors and estimate the time-varying volatility spillovers using a 200-day rolling sample framework. Additionally, the optimal lag length for each bivariate VAR model has been set by means of the AIC/BIC criteria. Note that even though the Diebold and Yilmaz (2012) results are based on vector autorregressions of order 4, these authors report that the total spillover plot is sensitive neither to the lag order of the VAR nor the choice of forecast horizon. 
between the spot and futures markets of the CAC40, DAX30 and FTSE100 indexes for each VAR model defined in the previous sections. Thus, the originality of our research lies in the fact that in order to determine which market is net sender and which market is net recipient of volatility spillovers, we use four input data based on high-frequency data on a five-minute interval basis: a) The daily volatilities of returns obtained using raw returns and the RGARCH model (VAR A), b) the daily volatilities obtained utilizing raw returns and the RV model (VAR B), c) the daily volatilities of returns computed employing standardized returns and the RGARCH model (VAR C); and, d) the daily volatilities calculated by using standardized returns and the RV approach (VAR D).

To quantify the contribution of the spot (futures) market to the volatility shocks in the futures (spot) market in net terms, we study the NPVS between these markets. The NPVS graphics allow us to analyse the evolution of the net directional spillovers among the spot and futures markets and to identify which markets are the net transmitters and receivers of spillovers and the main contributors to total spillovers ${ }^{29}$.

\section{[INSERT FIGURES 7 TO 9]}

Figure 7(CAC40), Figure 8(DAX 30) and Figure 9 (FTSE100) report the variation over time in the NPVS between the spot and futures market when daily volatilities have been calculated by means of the RGARCH and RV methodologies by using raw and standardized returns. Note that, net volatility tends to switch between positive and negative values in the three indexes during the period analysed. This occurs

\footnotetext{
${ }^{29}$ The net spillover for the spot market is calculated as a positive value, indicating that the spot market transmits spillovers to the futures market. On the contrary, when the net spillover has a negative value, the spot market receives spillovers from the futures market.
} 
in such a way that positive values mean that the spot market is a net transmitter of volatility to the futures market, and conversely, when the net spillover has a negative value, the spot market is a net receiver. Additionally, to display the information in a clearer way, we also depict in Figure 10 the mean of the net directional spillovers from the spot market to the futures market.

\section{[INSERT FIGURE 10]}

It is worth noting that, when raw returns are used in this analysis, results regarding which market is on average the greatest contributor of volatility in net terms are ambiguous. For the CAC40 and DAX30 indexes, according to the VAR A model, the futures market is on average a net volatility transmitter for most of the sample period (Figures 7.1 and 8.1), contrariwise, the VAR B model show that it is the spot market (Figures 7.2 and 8.2). On the other hand, for the FTSE100 index, results from the VAR A and B models (Figures 9.1 and 9.2) suggest that the spot market is on average the greatest net contributor of volatility spillovers. These results become more evident by looking at Figure 10. When the mean of net directional spillovers has positive value (negative value) it implies that the spot market is, on average, a net sender (a net receiver) of volatility spillovers (see, for instance that for the CAC40 index, according to the VAR A and B models the mean of net directional spillover is 1.69 and 0.24 respectively, thus it means that the spot market is a net receiver and a net sender respectively).

The presence of seasonality in high-frequency data and the fact that neither the VAR A model nor the VAR B model consider the intraday periodic component before implementing the Diebold and Yilmaz (2012) approach, makes us think that previous findings might be unreliable and should be interpreted with caution. 
Therefore, the next challenge is to remove intraday seasonality before estimating the NPVS. Figures 7.3 and 7.4 (CAC40 index), 8.3 and 8.4 (DAX30), and 9.3 and 9.4 (FTSE100) depict the NPVS after removing the intraday periodic component. Results suggest that the spot market is the largest net sender of volatility spillovers to the futures market throughout the entire sample ${ }^{30}$. Only the VAR C model for the FTSE100 index finds evidence that the futures market is the largest net sender of volatility spillovers. Hence, these results mostly support the idea of the dominant role of the spot market as net transmitter of volatility spillovers.

Looking at the graphics, it is also worth emphasizing that in terms of magnitude, the NPVS are greater in those models in which intraday seasonality has been removed (VAR C and VAR D models). This suggests, once more, that when the intraday periodic component is neglected (VAR A and B models), we might be losing some relevant information regarding the volatility transmission. The analysis indicates that there is volatility transmission across both markets. However, the dropping effect from the spot market to the futures market is higher after removing seasonality. In this sense, if volatility is understood as a measure of information flow (Ross 1989), then it can be accepted that the main source of information emanates from the spot market and it is spread into the futures market. Differences in transactions costs, nonsynchronous trading, short selling restrictions and other imperfections may be the reason for this smaller capability of the spot market to deal with unexpected shocks (Meneu and Torró 2003). Also, stock price pressure strongly related to return reversals, order imbalances, and illiquidity in stocks can also play a role in these findings (Goncalves-Pinto et. al, 2018). Moreover, the fact that volatility interdependence plays a key role in investment

\footnotetext{
${ }^{30}$ All cases involved except one, support this finding.
} 
and risk decision-making, and differences in volatilities may be used to pursue successful strategies (Chuliá and Torró 2008), this spillover comprises significant economic information in the sense of Ross (1989).

In the next section, we analyse how important it is to address the problem of microstructure noise when using high-frequency in volatility modelling, and to what extent results change after removing it.

\section{Robustness checks: considering microstructure noise}

Some studies show that realized variance may be sensitive to market frictions when applied to returns on a one-minute or less interval basis (Zhou 1996). The recent multivariate kernel estimator proposed by Barndorff-Nielsen et al. (2011) is a powerful tool to overcome this drawback. Although we have relied on the five-minute frequency in our study, which is regarded as the optimal frequency that makes market microstructure noise not detrimental, we additionally implement in this section the kernel based estimator (Barndorff-Nielsen et al. 2011) to address this problem and analyse the effect on results.

As expected, the findings after addressing the market microstructure noise are similar to those encountered so far. The VAR analysis reveals once more, that the number of lags is higher in those models in which raw data has been used, reinforcing the idea of spurious causality in those models that do not consider the problem of seasonality ${ }^{31}$.

With regard to the IRF, in line with the previous findings, results reveal that when a shock hits the system, the persistence of a shock in any market is much more

\footnotetext{
${ }^{31}$ Results are available upon request.
} 
persistent when raw data are employed. Figure 11 exhibits the persistence of a shock in each of the four models implemented for each index. See the way in which persistence dramatically diminishes in the VAR C and VAR D models (for instance, notice that for the CAC40 index the persistence in the VAR A and B models is 200 and 60 days respectively, whereas in the VAR $\mathrm{C}$ and D models, is 20 and 6 days respectively, note that the rest of the indexes follow the same pattern). Thus, it is evident that intraday seasonality is a key component to consider when modelling volatility at higher frequencies.

\section{[INSERT FIGURE 11]}

In terms of net directional spillovers, after removing intraday seasonalities, (VAR C and VAR D models), results seem to reinforce once again the idea that it is the spot market the net sender of volatility spillovers and that, in terms of magnitude, the NPVS is greater in those models in which the intraday periodic component has been removed.

Notice in Figure 12 that results are similar to those found in section 5.3, that is to say, when intraday seasonality is removed (VAR C and VAR D), the mean net directional spillover from the spot to the future market has positive value and is $\operatorname{higher}^{32}$.

\section{[INSERT FIGURE 12]}

Therefore, our results corroborate the idea that the impact of microstructure noise is not significant when an optimal frequency of observations is considered (Andersen 2000, Andersen et al. 2001, Pooter et al. 2008), and underpin the key role of

\footnotetext{
${ }^{32}$ As obtained in section 5.3, all cases involved except one, the VAR C in the FTSE100 index, support this finding.
} 
intraday seasonality in analysing volatility transmission when using high-frequency data.

\section{Conclusions}

In the last decades, the interest in studying the interaction between the financial markets has increased dramatically. Significant attention has been paid to examine the volatility transmission mechanism that exists in major financial equity markets. Needless to say, understanding volatility spillover is important by virtue of the critical repercussions for monetary policy, optimal resource allocation, risk measurement, capital requirements and asset valuation. Additionally, the growing availability of high-frequency data has boosted research on intraday data which has emerged as a major area in econometrics and statistics.

However, handling high-frequency data may be especially challenging because of the idiosyncrasy of the data, which makes it crucial to consider the intraday seasonal patterns present in the volatility of financial markets before modelling the dynamics of intraday volatility. Microstructure noise is another drawback associated with high-frequency data. Notwithstanding, some studies suggest that this problem may be overcome by using an optimal frequency of observations of five-minutes. This research, in line with these studies related to volatility transmission, corroborates that the impact of microstructure noise is negligible when observations on a five-minute interval basis are considered.

Thus, in this article, our focus of attention is on the intraday seasonality, and we aim to address if the well-documented strong intraday repetitive pattern in average absolute returns is present in our data and if there is any change in volatility 
transmission dynamics when the intraday periodic component is considered. Regarding this, the most remarkable results are summarised as follows: a) Noteworthy similarities in the intraday seasonal pattern are detected in the markets analysed; all of them illustrate a distorted double U-shape in the average absolute returns during a trading day; b) the FFF methodology used to remove the intraday periodic component considerably reduces serial autocorrelation; c) cross-serial correlation analysis reveals significant cross-market volatility interactions between the spot and futures markets that have also diminished noticeably after considering the seasonal pattern; d) volatility transmission differs significantly regardless of whether raw and standardized returns are considered, so that when intraday data are not standardized, the optimal number of lags in the VAR model determined by the selection criteria seems to be redundant; e) when a shock hits the system and the intraday periodic component has not been used to adjust the returns before conducting the spillover analysis, the response to that shock is highly persistent; and f) the directional measurement of volatility spillovers shows that the spot market is the largest net sender of volatility spillovers to the futures market and that, in terms of magnitude, the NPVS are generally greater when the intraday periodic component has been considered, which suggests, once again, that when this seasonal component is neglected, we might be losing some relevant information regarding volatility transmission.

In sum, this article highlights how high-frequency data can shed new light on issues concerning the volatility spillover between markets and why it is really important to remove the seasonal component to diminish the risk of spurious causality when using intraday data in volatility modelling. 
References

[1]Abhyankar, A. H. (1995). Return and volatility dynamics in the FTSE 100 stock index and stock index futures markets. Journal of Futures Markets, 15(4), 457-488.

[2] Andersen, T. G. (2000). Some reflections on analysis of high-frequency data. Journal of Business and Economic Statistics, 18(2), 146-153

[3] Andersen, T. G. and Bollerslev, T. (1997).Intraday periodicity and volatility persistence in financial markets. Journal of Empirical Finance, 4(2), 115-158

[4] Andersen, T. G. and Bollerslev, T. (1998). Answering the skeptics: Yes, standard volatility models do provide accurate forecasts. International economic review, 885-905

[5] Andersen, T. G., Bollerslev, T. and Cai, J. (2000). Intraday and interday volatility in the Japanese stock market. Journal of International Financial Markets, Institutions and Money, 10(2), 107-130

[6] Andersen, T. G., Bollerslev, T., Diebold, F. X. and Ebens, H. (2001). The distribution of realized stock return volatility. Journal of financial economics, 61(1), 4376

[7] Andersen, T. G., Bollerslev, T., Diebold, F. X. and Labys, P. (2001). The distribution of realized exchange rate volatility. Journal of the American Statistical Association, 96(453), 42-55

[8] Andersen, T. G., Bollerslev, T., Diebold, F. X. and Labys, P. (2003). Modeling and forecasting realized volatility. Econometrica, 71(2), 579- 625 
[9] Bandi, F.M. and Russell J.R. (2006). Separating microstructure noise from volatility. Journal of Financial Economics, 793, 655-692

[10] Barndorff-Nielsen, O. E., Hansen, P. R., Lunde, A. and Shephard, N. (2008). Designing realized kernels to measure the ex post variation of equity prices in the presense of noise. Econometrica, 76(6), 1481-1536

[11] Barndorff-Nielsen, O. E., Hansen, P. R., Lunde, A. and Shephard, N. (2011). Multivariate realised kernels: consistent positive semi-definite estimators of the covariation of equity prices with noise and nonsynchronous trading. Journal of Econometrics, 162(2), 149-169

[12] Barndorff-Nielsen, O. E. and Shephard, N. (2002). Econometric analysis of realized volatility and its use in estimating stochastic volatility models. Journal of the Royal Statistical Society: Series B (Statistical Methodology), 64(2), 253-280

[13] Berument, H. and Kiymaz, H. (2001). The day of the week effect on stock market volatility. Journal of Economics and Finance, 25(2), 181- 193

[14] Brooks, C., Garret, I. and Hinnich, M.J. (1999). An alternative approach to investigating lead-lag relationships between stock and stock index futures markets. Applied Financial Economics, 9(6), 605-613

[15] Chan, K., Chan, K. C. and Karolyi, G. A. (1991). Intraday volatility in the stock index and stock index futures markets. The Review of Financial Studies 4(4), 657-684

[16] Chow, Y., Yung, H. and Zhang, H. (2003). Expiration day effects: The case of Hong Kong. Journal of Futures Markets, 23(1), 67-86

[17] Diebold, F. X. and Yilmaz, K. (2009). Measuring financial asset return and volatility spillovers, with application to global equity markets. The Economic Journal, 119(534), 158-171 
[18] Diebold, F. X., and Yilmaz, K. (2012). Better to give than to receive: Predictive directional measurement of volatility spillovers. International Journal of Forecasting, $28(1), 57-66$

[19] Duong, H. N. and Kalev, P. S. (2008). The Samuelson hypothesis in futures markets: An analysis using intraday data. Journal of Banking and Finance, 32(4), 489500

[20] Engle, R. (2001). GARCH 101: The use of ARCH/GARCH models in applied econometrics. The Journal of Economic Perspectives, 15(4), 157-168

[21] Fung, J. K., Lien, D., Tse, Y. and Tse, Y. K. (2005). Effects of electronic trading on the Hang Seng Index futures market. International Review of Economics and Finance, 14(4), 415-425

[22] Gallant, A. R. (1981). On the bias in flexible functional forms and an essentially unbiased form: the Fourier flexible form. Journal of Econometrics, 15(2), 211-245. 23] Gallant, A. R. (1982). Unbiased determination of production technologies. Journal of Econometrics, 20(2), 285-323

[24] Goncalvez-Pinto, L., Grundy, B.D., Hameed, A., Van der Hejden, T. and Zhu, Y. (2018). Why Do Option Prices Predict Stock Returns? The Role of Price Pressure in the Stock Market. FIRN Research Paper No. 2695145

[25] Goodhart, C. A. and O’Hara, M. (1997). High-frequency data in financial markets: Issues and applications. Journal of Empirical Finance, 4(2-3), 73-114

[26] Han, L. M., Kling, J. L. and Sell, C. W. (1999). Foreign exchange futures volatility: Day-of-the-week, intraday, and maturity patterns in the presence of macroeconomic announcements. Journal of Futures Markets, 19(6), 665-693

[27] Hancock, G. D. (1993). Whatever happened to the triple witching hour? Financial Analysts Journal, 49(3), 66-72 
[28] Hansen, P. R., Huang, Z. and Shek, H. H. (2012). Realized garch: a joint model for returns and realized measures of volatility. Journal of Applied Econometrics, 27(6), $877-906$

[29] Hansen, P. R. and Lunde, A. (2006). Realized variance and market microstructure noise. Journal of Business and Economic Statistics, 24(2), 127-161

[30] Hansen, P. R., Lunde, A. and Voev, V. (2014). Realized beta GARCH: a multivariate GARCH model with realized measures of volatility. Journal of Applied Econometrics, 29(5), 774-799

[31] Harju,K. and Hussain, S.M. (2011). Intraday seasonalities and macroeconomic news announcements. European Financial Management, 17(2), 367-390

[32] Harris, L. (1986). A transaction data study of weekly and intradaily patterns in stock returns. Journal of Financial Economics, 16(1), 99-117

[33] Herbst, F.A., McCormack, J.P. and West, E.N. (1987). Investigation of the lead-lag relationships between spot stock indices and their futures contracts. Journal of Futures Markets, 7(4), 373-381

[34] Kan, A.C.N. (2001). Expiration-day effect: evidence from high-frequency data in the Hong Kong stock market. Applied Financial Economics, 11(1), 107-118

[35] Karolyi, A. G. (1996) Stock market volatility around expiration days in Japan, The Journal of Derivatives, 4(2), 23-43

[36] Kawaller, I. G., Kock, P. D. andKoch, T. W. (1987). The temporal relationship between S\&P 500 futures prices and the S\&P 500 index. The Journal of Finance, 42(5), 1309-1329

[37] Kawaller, I. G., Koch, P. D. and Koch, T. W. (1990). Intraday relationships between volatility in S\&P 500 futures prices and volatility in the S\&P 500 index. Journal of Banking and Finance, 14(2-3), 373-397 
[38] Kiymaz, H. and Berument, H. (2003). The day of the week effect on stock market volatility and volume: International evidence. Review of Financial Economics, 12(4), $363-380$

[39] Kofman, P. and Martens, M. (1997). Interaction between stock markets: an analysis of the common trading hours at the London and New York stock exchange. Journal of International Money and Finance, 16(3), 387- 414

[40] Koutmos, G. and Tucker, M. (1996). Temporal relationships and dynamic interactions between spot and futures stock markets. Journal of Futures Markets, 16(1), $55-69$

[41] Martens, M., Chang, Y.-C., and Taylor, S. J.(2002). A Comparison of Seasonal Adjustment Methods When Forecasting Intraday Volatility. The Journal of Financial Research, 25(2), 283-299

[42] McAleer, M. and Medeiros, M. C. (2008). Realized volatility: A review. Econometric Reviews, 27(1-3), 10-45

[43] Meneu, V. and Torro, H. (2003). Asymmetric covariance in spot-futures markets. Journal of Futures Markets, 23(11), 1019-1046

[44] Merton, R. C. (1980). On estimating the expected return on the market: An exploratory investigation. Journal of Financial Economics, 8(4), 323- 361

[45] Pesaran, H. H. and Shin, Y. (1998). Generalized impulse response analysis in linear multivariate models, Economics Letters, 58(1), 17-29

[46] Pooter, M. D., Martens, M. and Dijk, D. V. (2008). Predicting the daily covariance matrix for S\&P 100 stocks using intraday data - but which frequency to use? Econometric Reviews, 27(1-3), 199-229 
[47] Ross, S. A. (1989). Information and volatility: the no-arbitrage martingale approach to timing and resolution irrelevancy. The Journal of Finance, 44(1), 1-17

[48] Samuelson, P. A. (1965). Proof that properly anticipated prices fluctuate randomly, Industrial Management Review, 6, 41-49

[49] Sims, C. A. (1980). Macroeconomics and reality. Econometrica, 48(1), 1-48

[50] Soriano, P., Climent, F.J., 2006. Volatility transmission models: a survey. Revista de Economía Financiera 10, 32-81

[51] Stoll, H. R. and Whaley, R. E. (1987). Program trading and expiration day effects. Financial Analysts Journal 43(2), 16-28

[52] Stoll, H. R. and Whaley, R. E. (1991). Expiration day effects: What has changed? Financial Analysts Journal, 47(1), 58-72

[53] Tse, Y. (1999). Price discovery and volatility spillovers in the DJIA index and futures markets. The Journal of Futures Markets, 19(8), 911- 930

[54] Wood, R. A., McInish, T. H. and Ord, J. K. (1985). An investigation of transactions data for NYSE stocks. The Journal of Finance, 40(3), 723-739

[55] Wu, C., Li, J. and Zhang, W. (2005). Intradaily periodicity and volatility spillovers between international stock index futures markets. Journal of Futures Markets, 25(6), $553-585$

[56] Zhang, L., Mykland, P.A. and Aït-Sahalia, Y. (2005). A tale of two time scales: determining integrated volatility with noisy high-frequency data. Journal of the American Statistical Association, 100, 1394-1411

[57] Zhou, B. (1996). High-frequency data and volatility in foreign-exchange rates. Journal of Business and Economic Statistics, 14(1), 45-52 


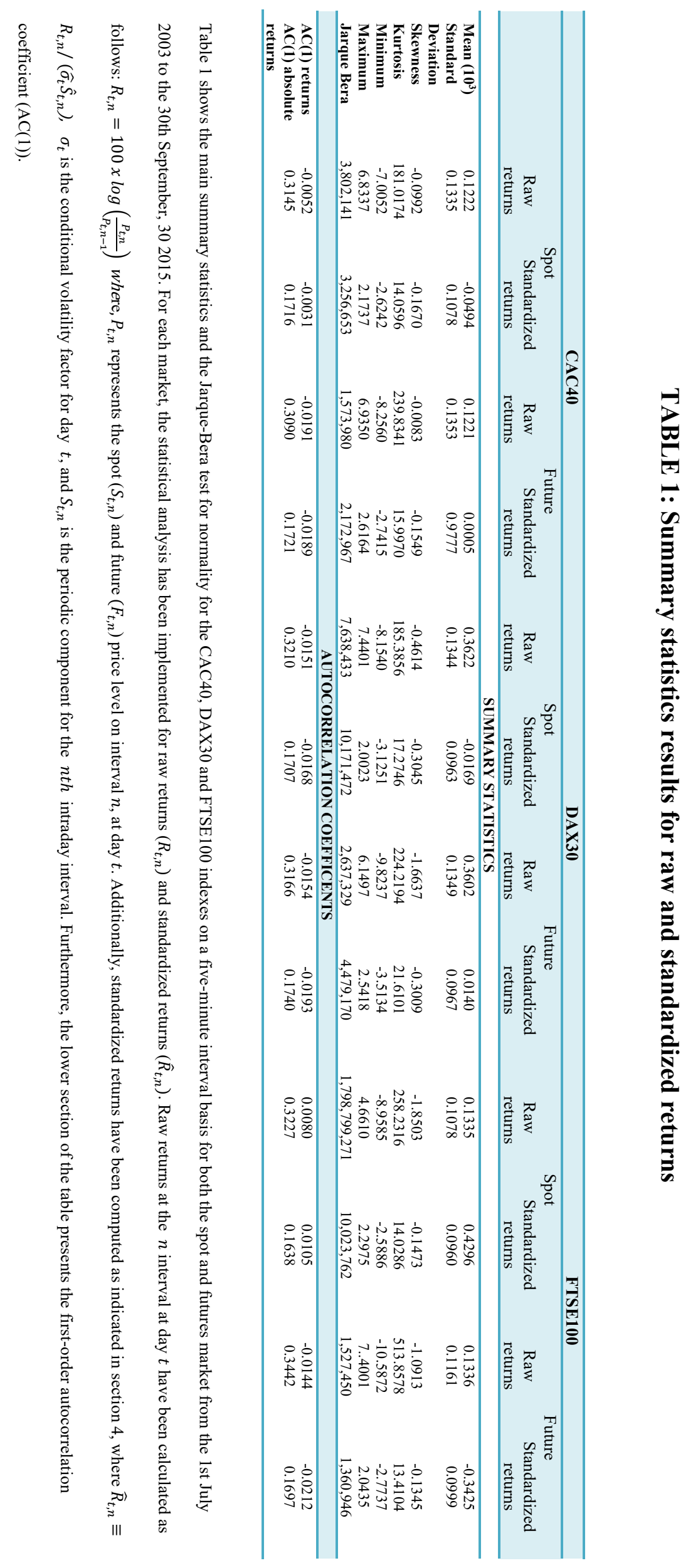




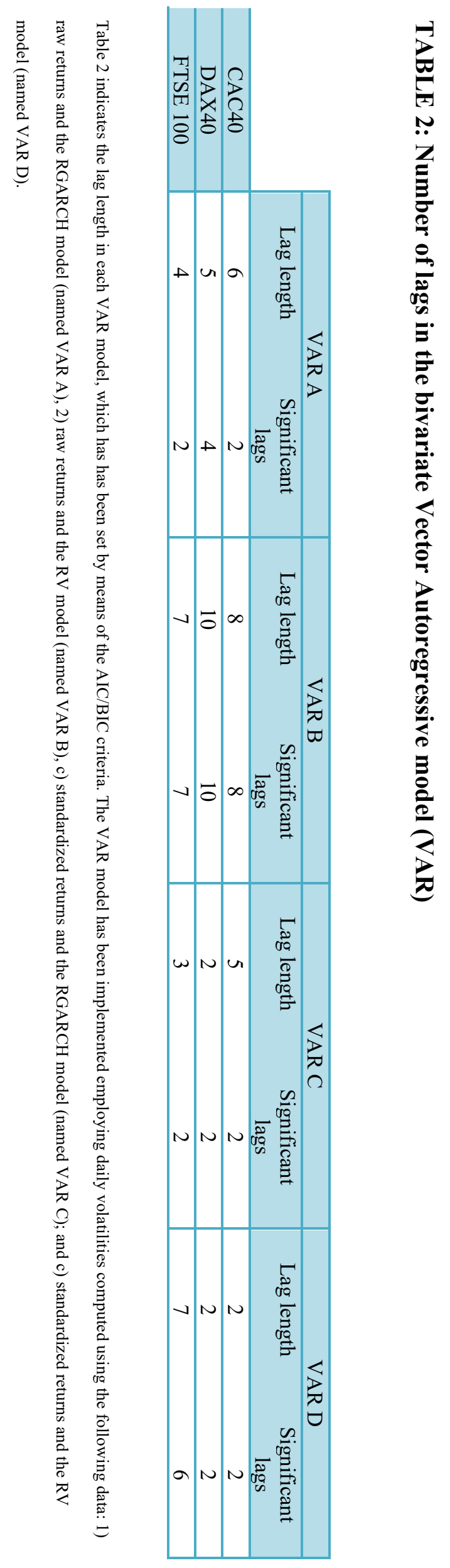


FIGURE 1: Mean absolute returns for CAC40, DAX30 and FTSE100 indexes

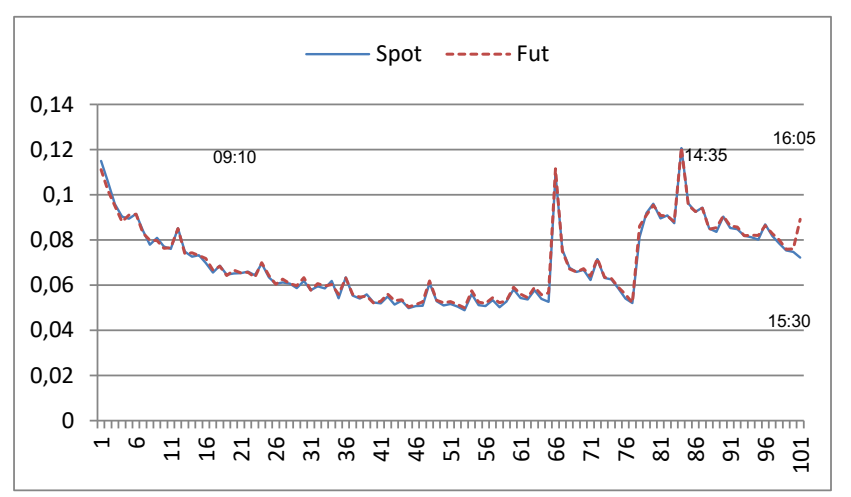

FIGURE 1.1: Mean absolute returns for CAC40

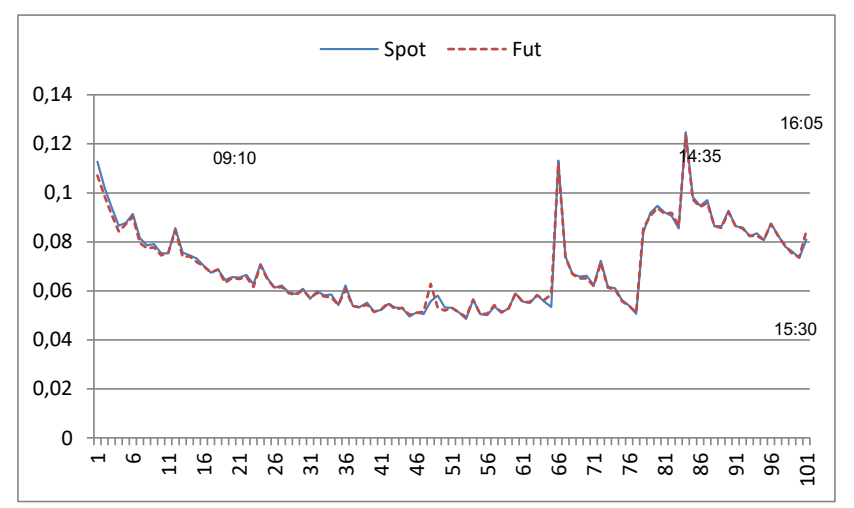

FIGURE 1.2: Mean absolute returns for DAX30

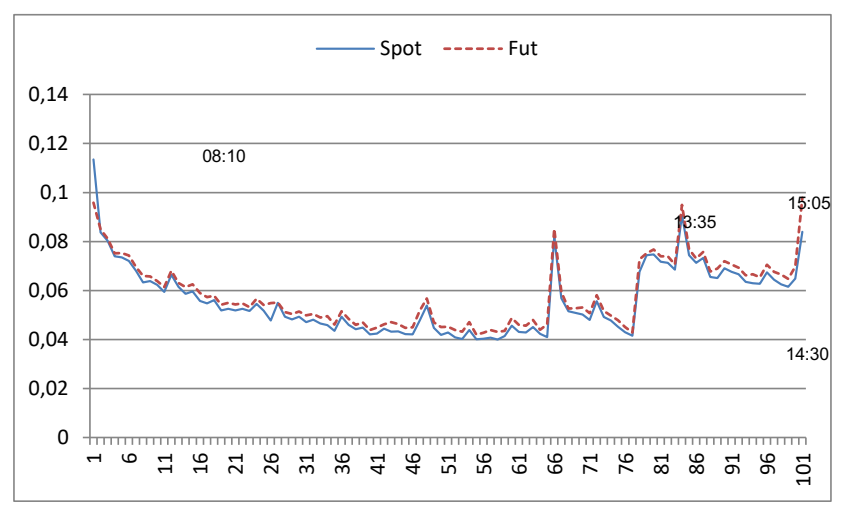

FIGURE 1.3: Mean absolute returns for FTSE100

FIGURE 1 reports the five-minute average absolute returns during a trading day for the stock index and the stock index futures of CAC40 (FIGURE 1.1), DAX30 (FIGURE 1.2) and FTSE100 (FIGURE 1.3) during the period from July 1, 2003 to September 30, 2015, for a total of 308 555, 310070 and 301182 observations for CAC40, DAX30 and FTSE100 respectively. The horizontal axis represents the number of five-minute intervals in a trading day. There are 101 intervals per day, so that observation 1 corresponds to 09:10 for CAC40 and DAX30 indexes, and 8:10 for FTSE100 and observation 101 corresponds to 17:30 for CAC40 and DAX30 indexes and 16:30 for FTSE100. The vertical axis represents the mean absolute returns.. 
FIGURE 2: Autocorrelogram for raw and standardized intraday absolute returns

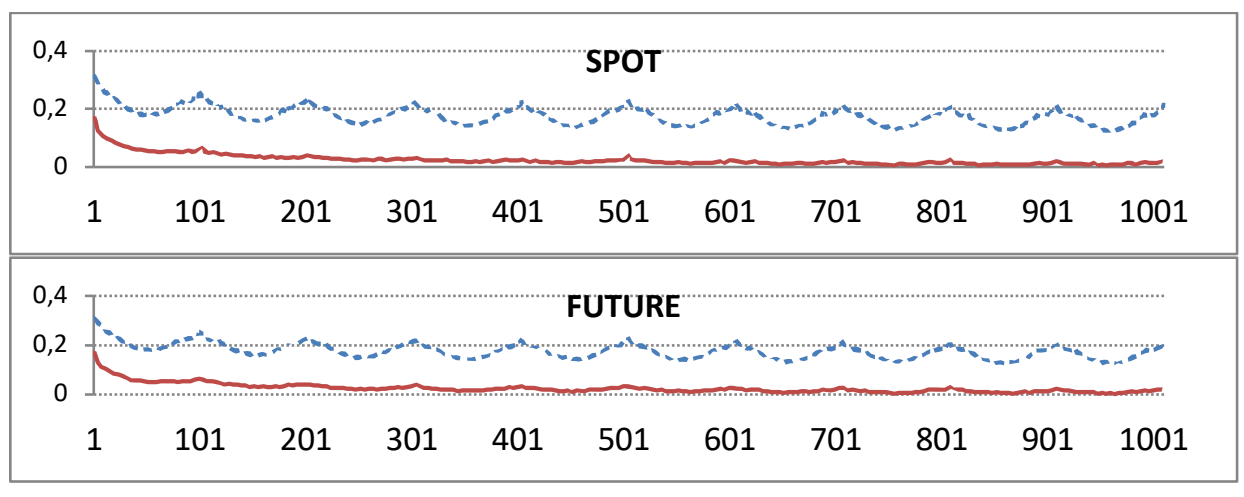

FIGURE 2.1: CAC40

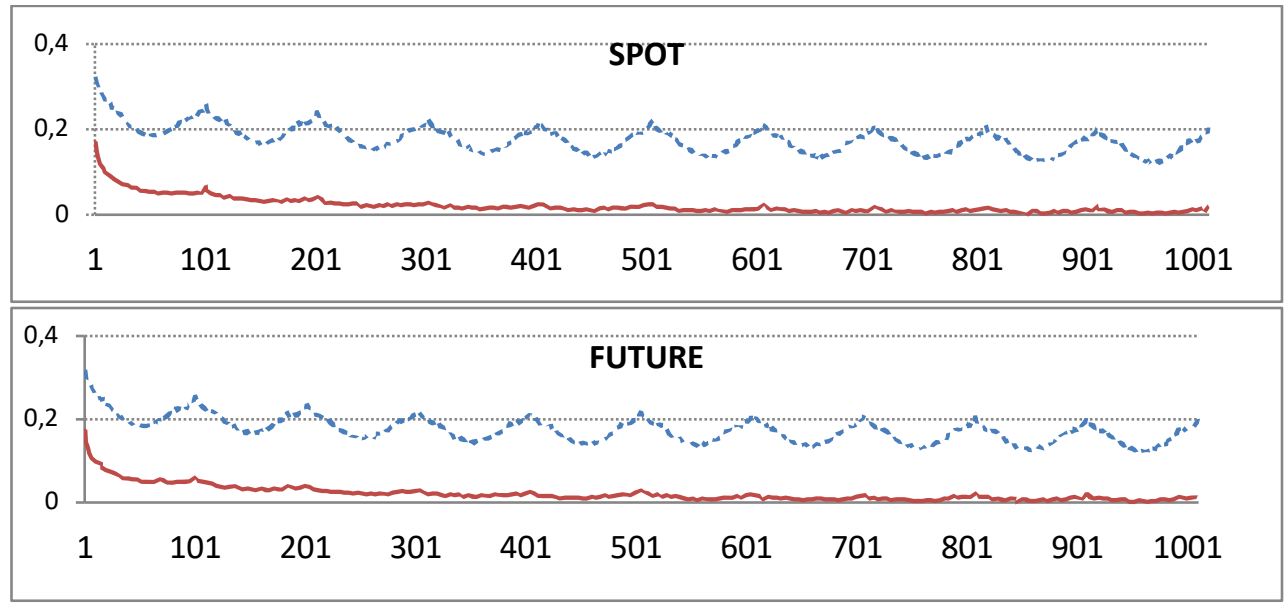

FIGURE 2.2: DAX30

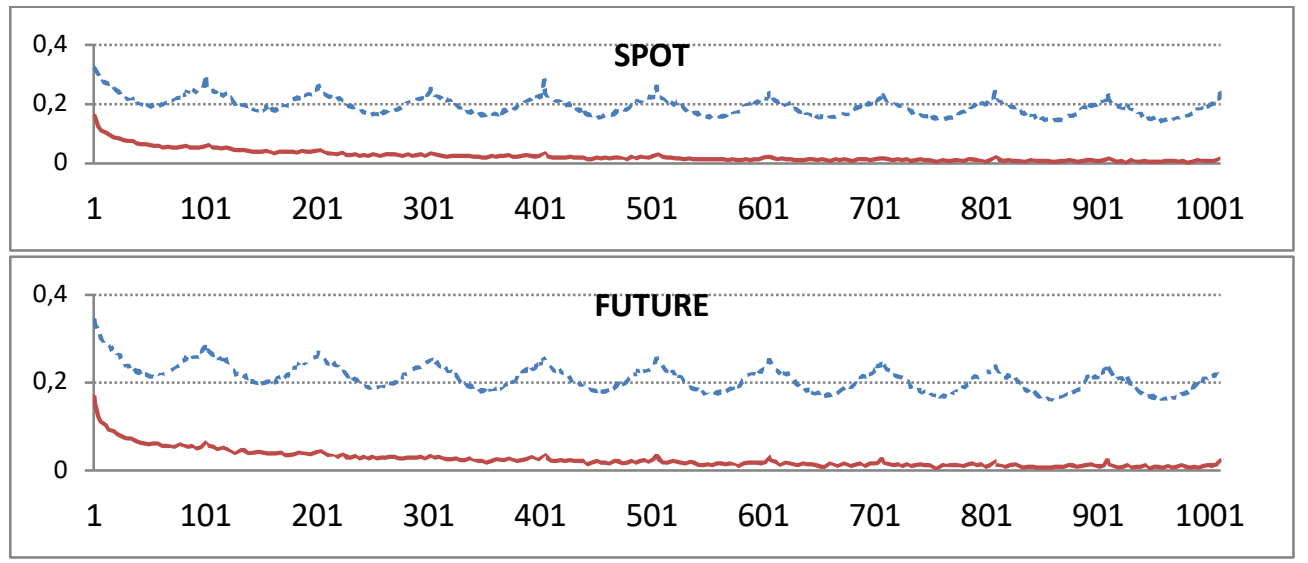

FIGURE 2.3: FTSE100

FIGURE 2 shows the autocorrelation pattern for the raw (dashed line) and standardized (solid line) five-minute absolute index returns up to a lag of 1010 (10 days with 101 intervals of five minutes per day). In each Figure (2.1, 2.2 and 2.3), the autocorrelogram for the index stock is depicted at the top, and the autocorrelogram for the index stock future is depicted at the bottom. The sample period extends from July 1, 2003 to September, 302015 for a total of 308 555, 310070 and 301182 observations for CAC40, DAX30 and FTSE100 respectively. The horizontal axis represents the lag length, and the vertical axis the magnitude of the autocorrelation coefficient. 


\section{FIGURE 3: Cross-serial correlations for raw and standardized five-minute intraday absolute returns}

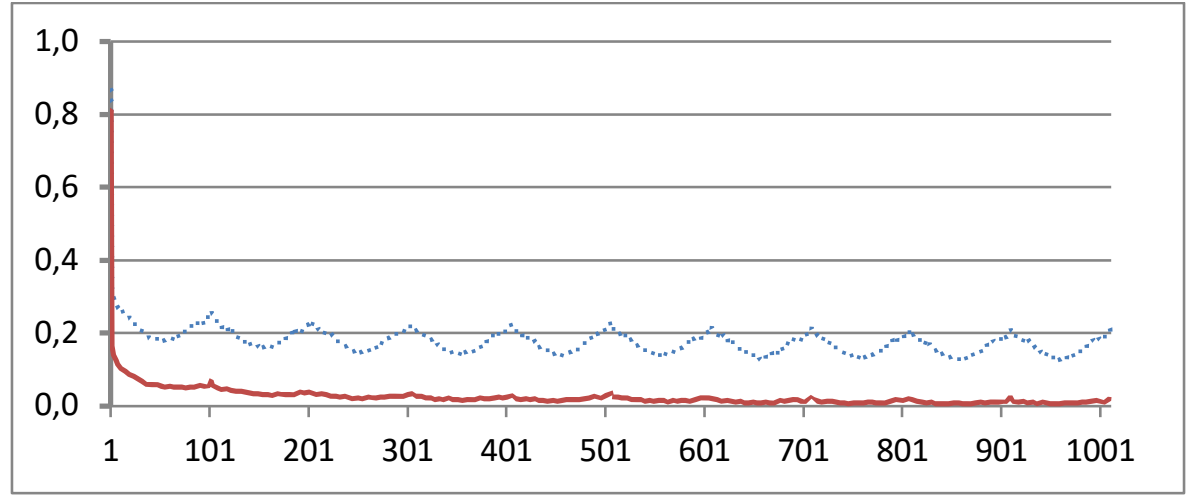

FIGURE 3.1 Cross-serial correlations for raw and standardized absolute returns for CAC40 index

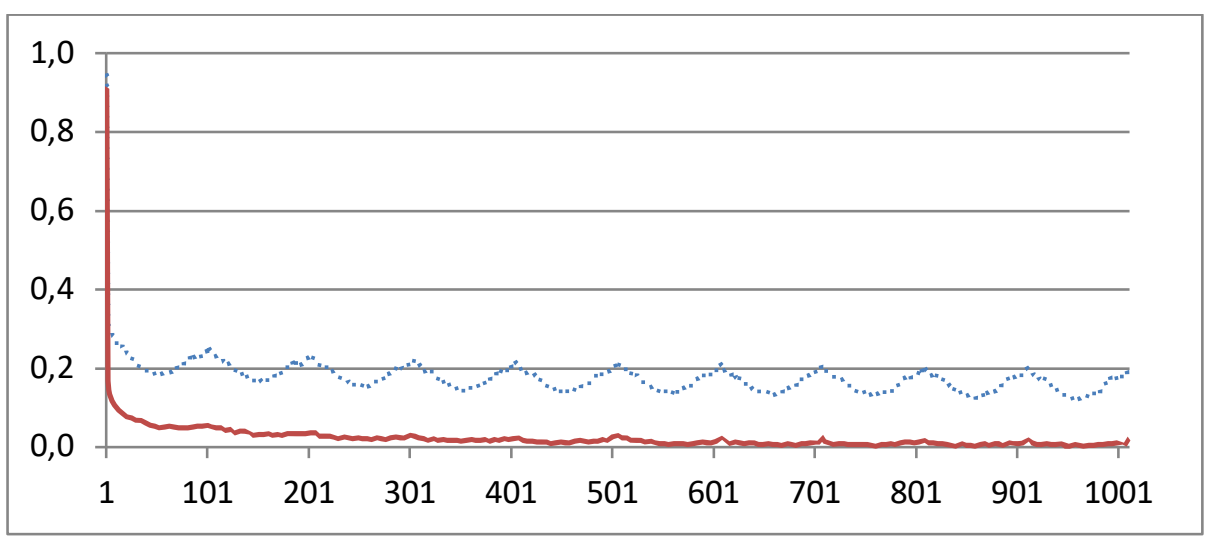

FIGURE 3.2 Cross-serial correlations for raw and standardized absolute returns for DAX30 index

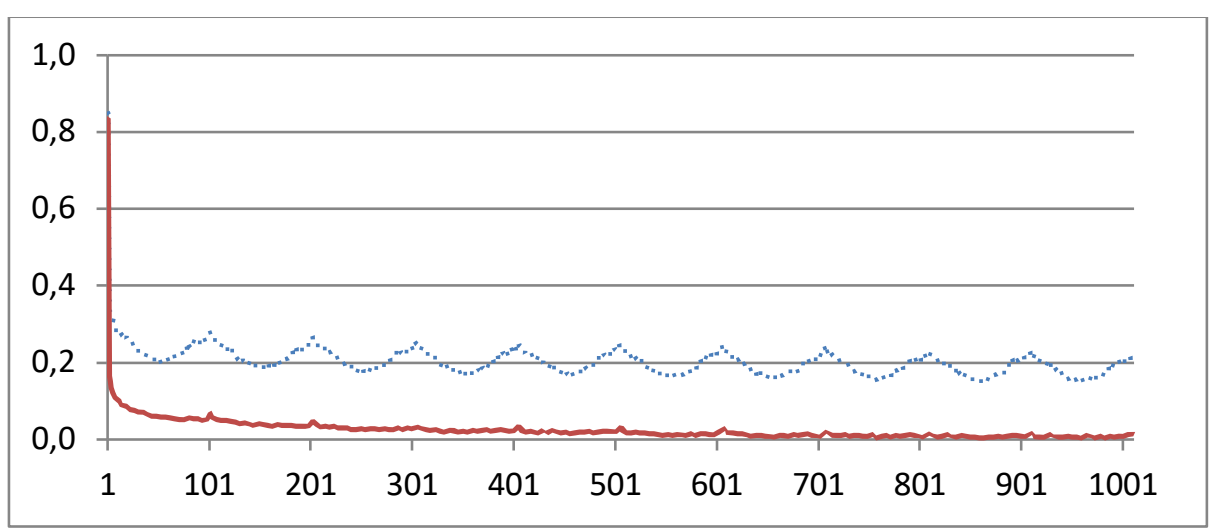

FIGURE 3.3 Cross-serial correlations for raw and standardized absolute returns for FTSE100 index

FIGURE 3 depicts the cross-serial correlations for five-minute intraday absolute returns between the stock index and the stock index futures up to ten days for raw (dashed line) and standardized returns (solid line) for the CAC40, DAX30 and FTSE100 indexes, up to a lag length of 1010 or 10 trading days (101 five-minute intervals per day). The sample period extends from July 1,2003 to September 30, 2015 for a total of 308 555, 310, 070 and 301182 observations for CAC40, DAX30 and FTSE100 respectively. The horizontal axis represents the lag length, and the vertical axis the magnitude of the cross-serial correlation coefficient. 
FIGURE 4: Impulse Response Function (IRF) for the CAC40 index
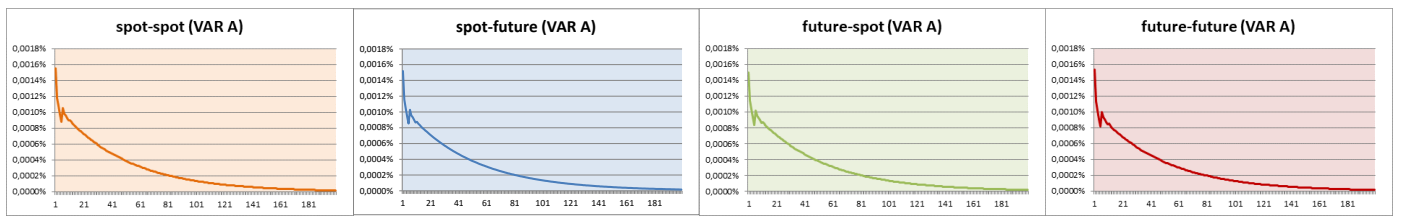

FIGURE 4.1: IRF for the CAC40 considering daily volatilities computed by means of the RGARCH using raw returns (named VAR A model)

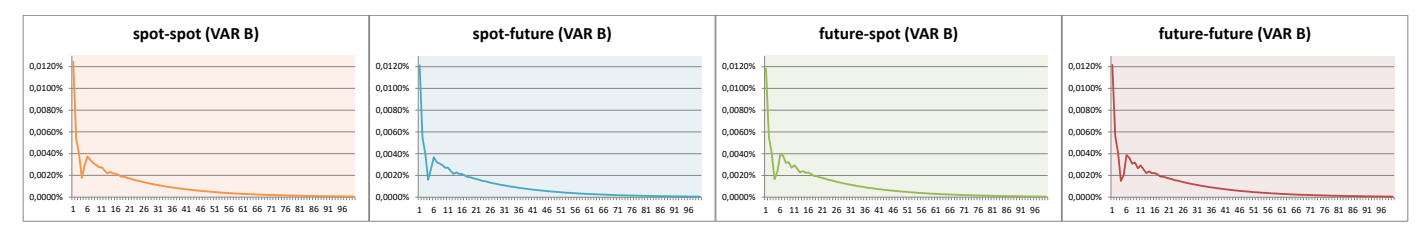

FIGURE 4.2: IRF for the CAC40 considering daily volatilities computed by means of the RV using raw returns (named VAR B model)

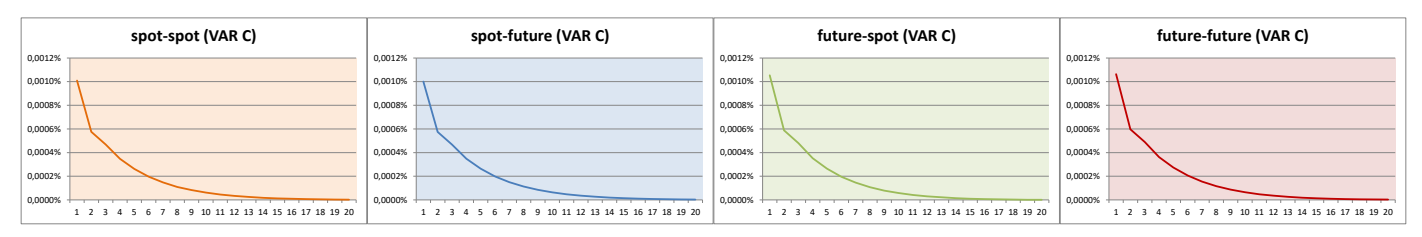

FIGURE 4.3: IRF for the CAC40 considering daily volatilities computed by means of the RGARCH using standardized returns (named VAR C model)

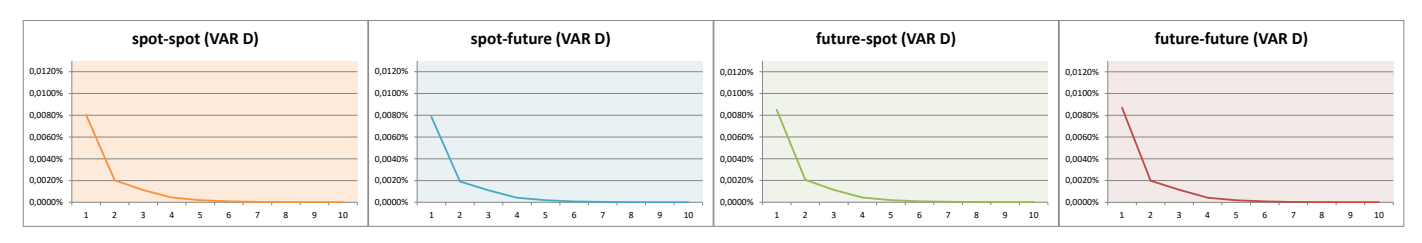

FIGURE 4.4: IRF for the CAC40 considering daily volatilities computed by means of the RV using standardized returns (named VAR D model)

FIGURE 4 exhibits the impulse response to a one standard deviation shock for DAX30 index considering the VAR A model (FIGURE 4.1), the VAR B model (FIGURE 4.2), the VAR C model (FIGURE 4.3) and the VAR D model (FIGURE 4.4). The horizontal axis represents the number of days and the vertical axis represents the magnitude of the shock expressed as a percentage of the volatility increase. figures spot-spot represent the impact on the spot market of an unexpected shock in the spot market, figures spot-future represent the impact on the futures market of an unexpected shock in the spot market, Figures future-spot represent the impact on the spot market of an unexpected shock in the futures market, and figures future-future represent the impact on the futures market of an unexpected shock in the futures market. 


\section{FIGURE 5: Impulse Response Function (IRF) for the DAX30 index}

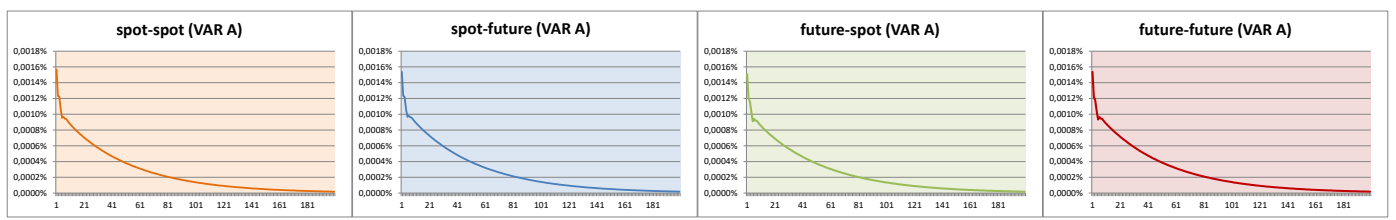

FIGURE 5.1: IRF for the DAX30 considering daily volatilities computed by means of the RGARCH using raw returns (named VAR A model)

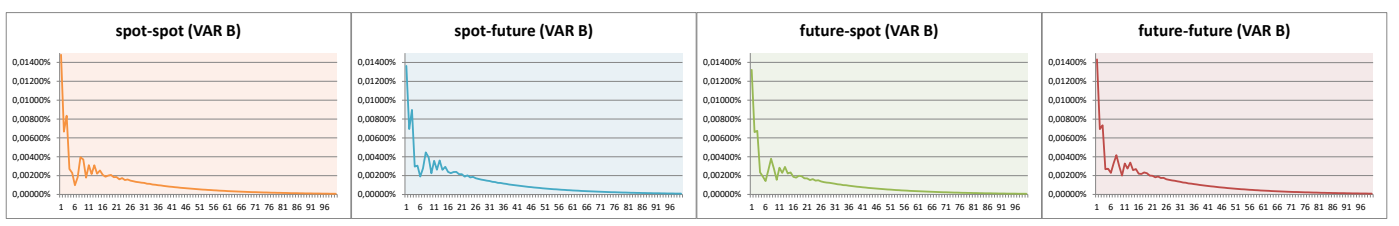

FIGURE 5.2: IRF for the DAX30 considering daily volatilities computed by means of the RV using raw returns (named VAR B model)

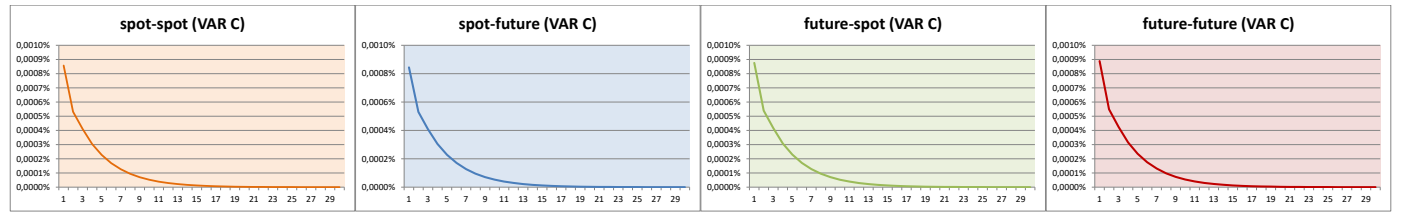

FIGURE 5.3: IRF for the DAX30 considering daily volatilities computed by means of the RGARCH using standardized returns (named VAR C model)

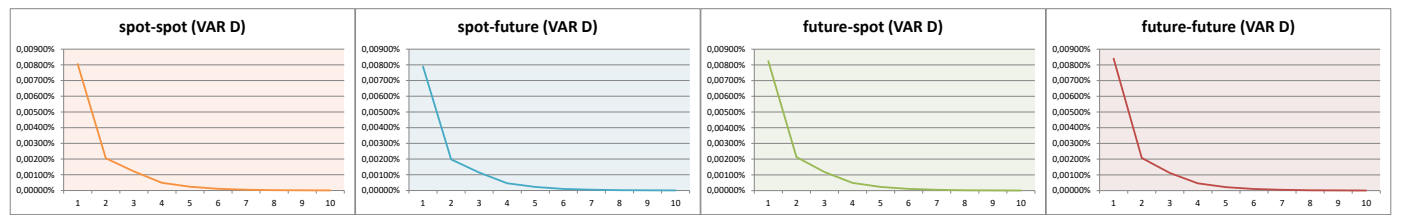

FIGURE 5.4: IRF for the DAX30 considering daily volatilities computed by means of the RV using standardized returns (named VAR D model)

FIGURE 5 exhibits the impulse response to a one standard deviation shock for DAX30 index considering the VAR A model (FIGURE 5.1), the VAR B model (FIGURE 5.2), the VAR C model (FIGURE 5.3) and the VAR D model (FIGURE 5.4). The horizontal axis represents the number of days and the vertical axis represents the magnitude of the shock expressed as a percentage of the volatility increase. Figures spot-spot represent the impact on the spot market of an unexpected shock in the spot market, figures spot-future represent the impact on the futures market of an unexpected shock in the spot market, figures future-spot represent the impact on the spot market of an unexpected shock in the futures market, and figures future-future represent the impact on the futures market of an unexpected shock in the futures market. 


\section{FIGURE 6: Impulse Response Function (IRF) for the FTSE100 index}

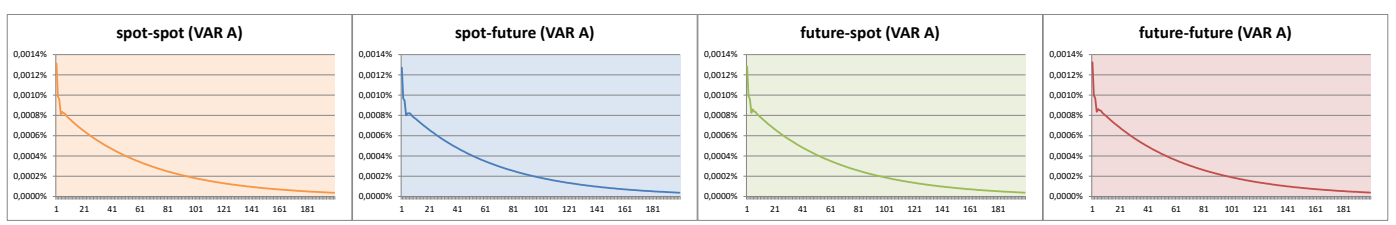

FIGURE 6.1: IRF for the FTSE100 considering daily volatilities computed by means of the RGARCH using raw returns (named VAR A model)

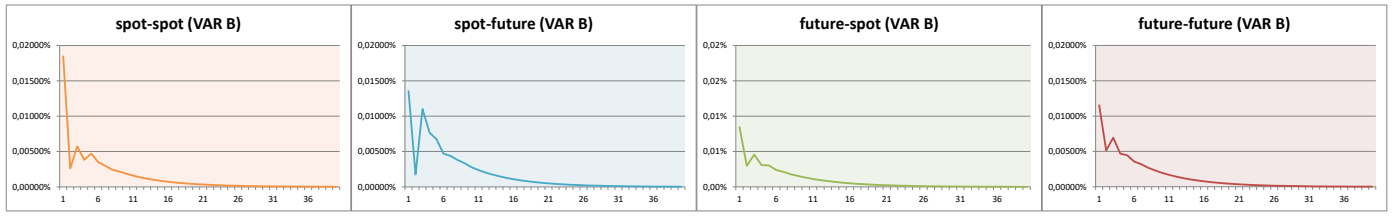

FIGURE 6.2: IRF for the FTSE100 considering daily volatilities computed by means of the RV using raw returns (named VAR B model)

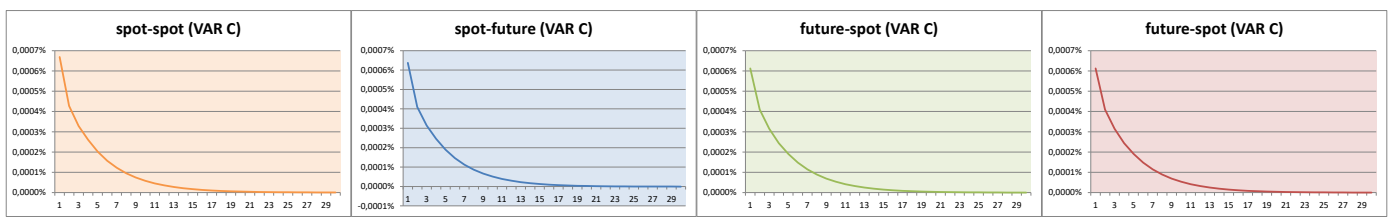

FIGURE 6.3: IRF for the FTSE100 considering daily volatilities computed by means of the RGARCH using standardized returns (named VAR C model)

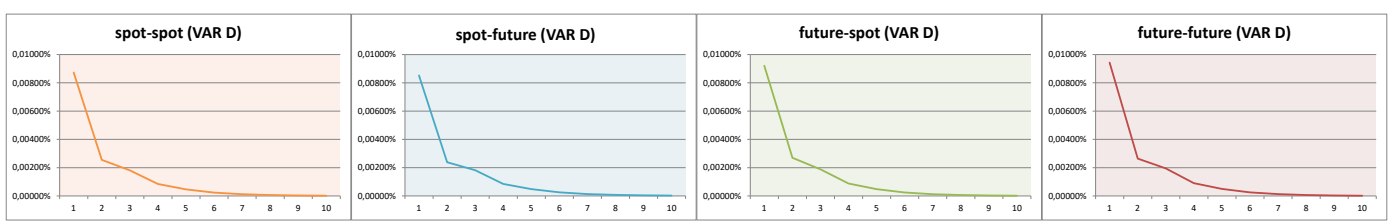

FIGURE 6.4: IRF for the FTSE100 considering daily volatilities computed by means of the RV using standardized returns (named VAR D model)

FIGURE 6 exhibits the impulse response to a one standard deviation shock for DAX30 index considering the VAR A model (FIGURE 6.1), the VAR B model (FIGURE 6.2), the VAR C model (FIGURE 6.3) and the VAR D model (FIGURE 6.4). The horizontal axis represents the number of days and the vertical axis represents the magnitude of the shock expressed as a percentage of the volatility increase. Figures spot-spot represent the impact on the spot market of an unexpected shock in the spot market, Figures spot-future represent the impact on the futures market of an unexpected shock in the spot market, Figures future-spot represent the impact on the spot market of an unexpected shock in the futures market, and Figures future-future represent the impact on the futures market of an unexpected shock in the futures market. 
FIGURE 7: Net pairwise volatility spillover between the CAC40 index and CAC40 index future

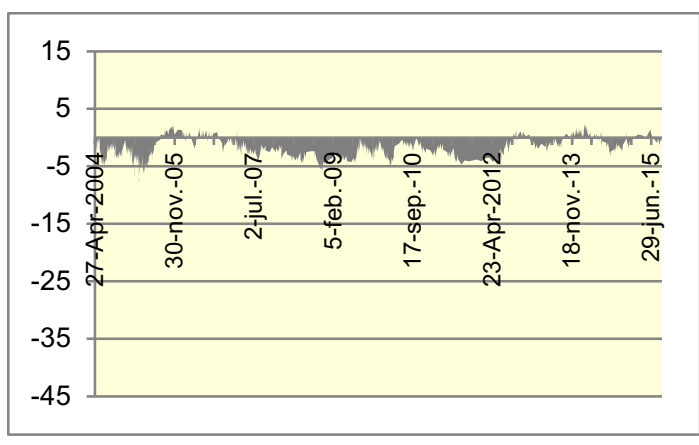

FIGURE 7.1 VAR A model (RGARCH with raw returns)

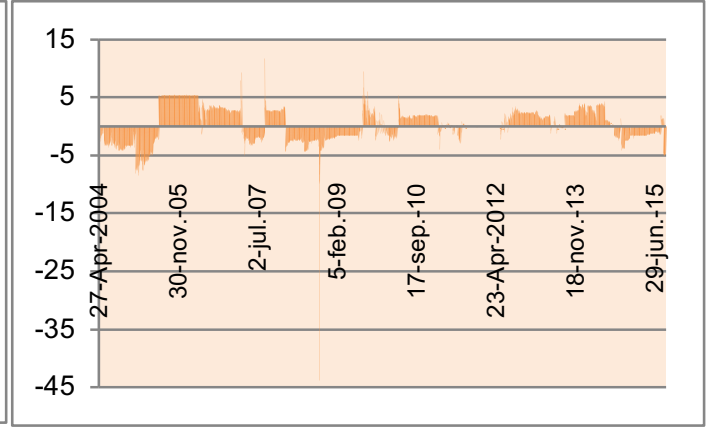

FIGURE 7.2 VAR B model (RV with raw returns)

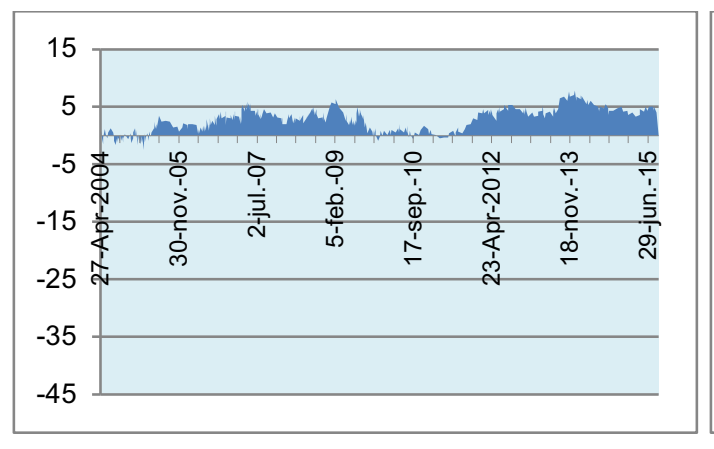

FIGURE 7.3 VAR C model (RGARCH with standardized returns)

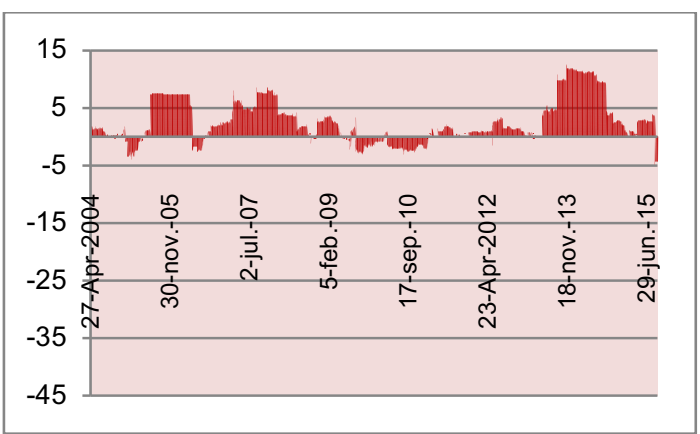

FIGURE 7.4 VAR D model (RV with standardized returns)

Figures 7.1, 7.2, 7.3 and 7.4 represent the net pairwise volatility spillover between the CAC40 index and CAC40 index future for the VAR A, VAR B, VAR C and VAR D models respectively. The horizontal axis represents the date (from April 2004 to September 2015 ) and the vertical axis represents the net spillover (expressed in terms of percentage). When the net spillover has positive value it indicates that the spot market transmits spillovers to the futures market. On the contrary, when the net spillover has negative value it means that the spot market receives spillovers from the futures market. 
FIGURE 8: Net pairwise volatility spillover between the DAX30 index and DAX30 index future

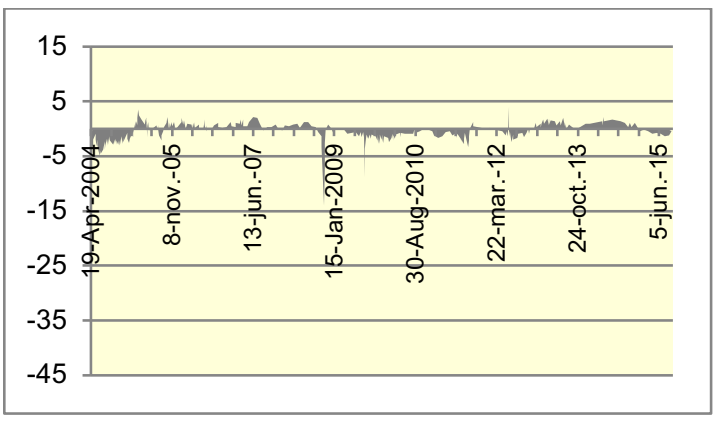

FIGURE 8.1 VAR A model (RGARCH with raw returns)

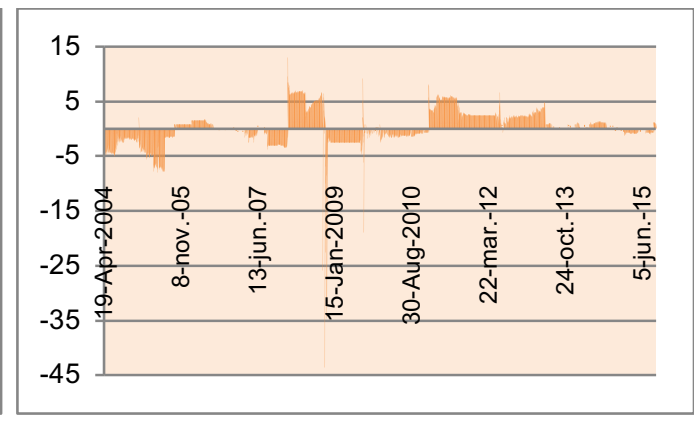

FIGURE 8.2 VAR B model (RV with raw returns)

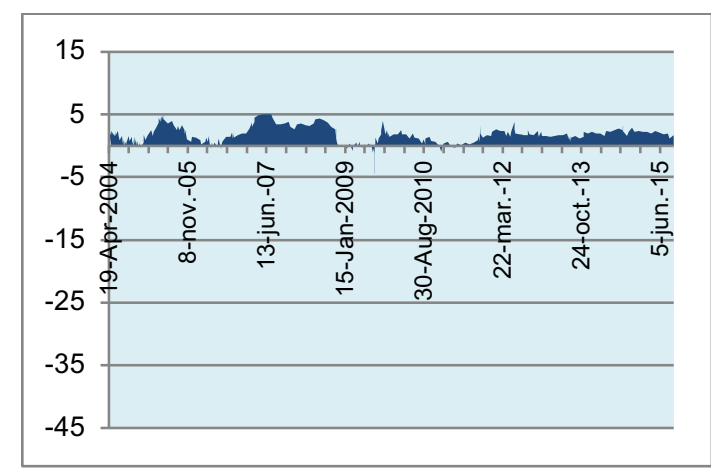

FIGURE 8.3 VAR C model

(RGARCH with standardized returns)

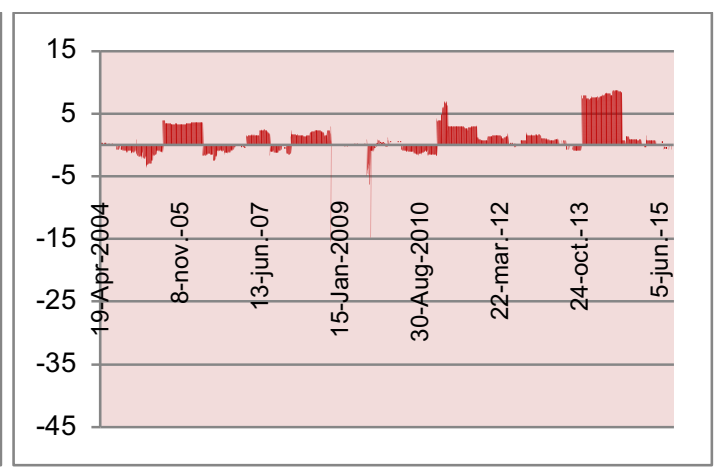

FIGURE 8.4 VAR D model (RV with standardized returns)

Figures 8.1, 8.2, 8.3 and 8.4 represent the net pairwise volatility spillover between the DAX30 index and DAX30 index future for the VAR A, VAR B, VAR C and VAR D models respectively. The horizontal axis represents the date (from April 2004 to September 2015) and the vertical axis represents the net spillover (expressed in terms of percentage). When the net spillover has positive value it indicates that the spot market transmits spillovers to the futures market. On the contrary, when the net spillover has negative value it means that the spot market receives spillovers from the futures market. 
FIGURE 9: Net pairwise volatility spillover between the FTSE100 index and FTSE100 index future

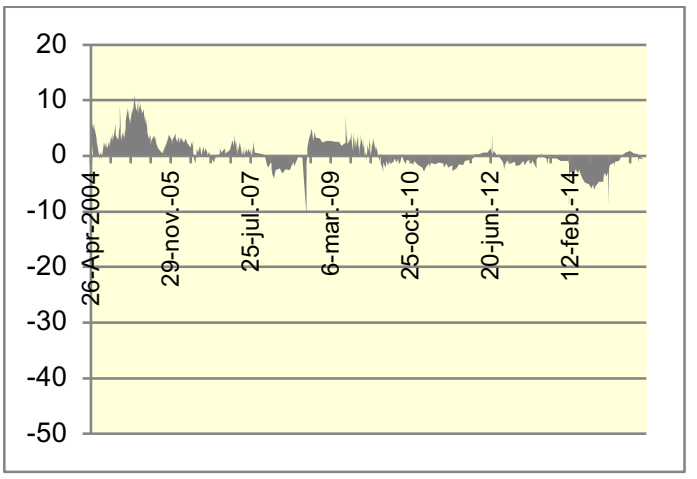

FIGURE 9.1 VAR A model (RGARCH with raw returns)

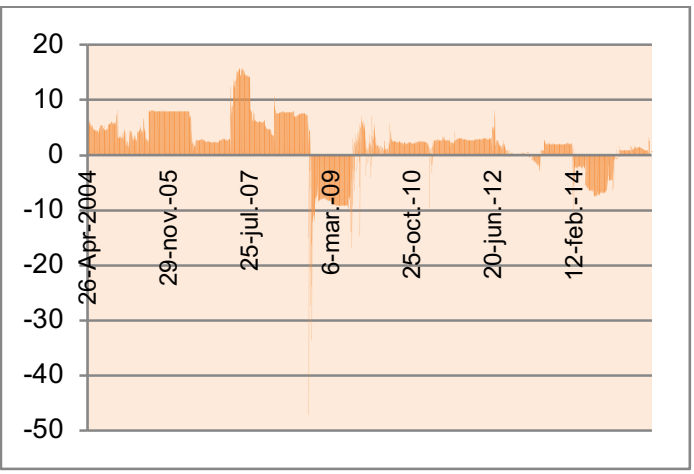

FIGURE 9.2 VAR B model (RV with raw returns)

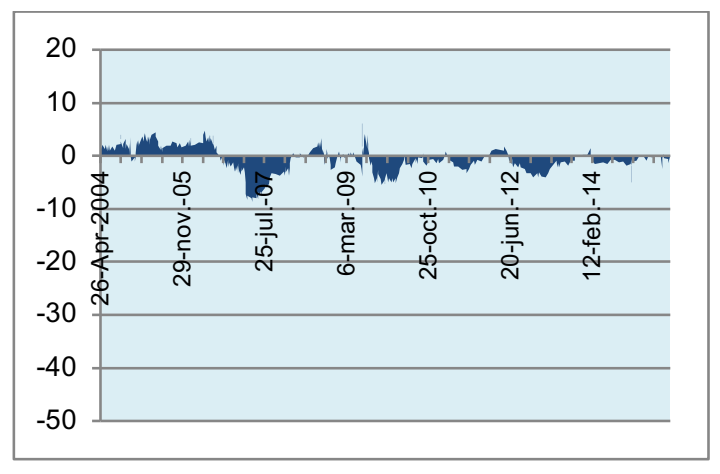

FIGURE 9.3 VAR C model

(RGARCH with standardized returns)

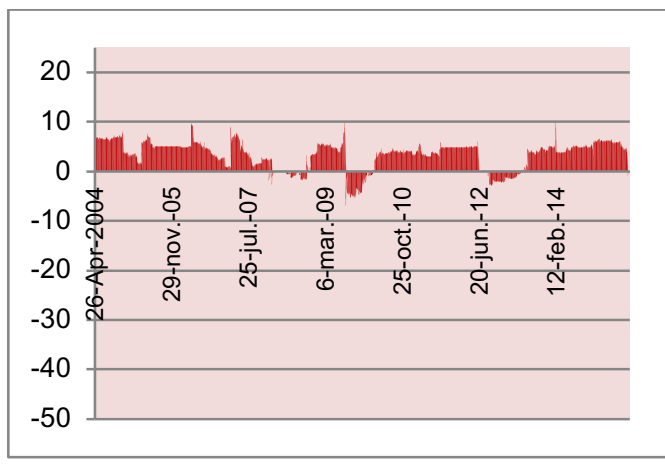

FIGURE 9.4 VAR D model (RV with standardized returns)

Figures 9.1, 9.2, 9.3 and 9.4 represent the net pairwise volatility spillover between the FTSE100 index and FTSE100 index future for the VAR A, VAR B, VAR C and VAR D models respectively. The horizontal axis represents the date (from April 2004 to September 2015) and the vertical axis represents the net spillover (expressed in terms of percentage). When the net spillover has positive value it indicates that the spot market transmits spillovers to the futures market. On the contrary, when the net spillover has negative value it means that the spot market receives spillovers from the futures market. 
FIGURE 10: Mean net directional spillover from spot to future market

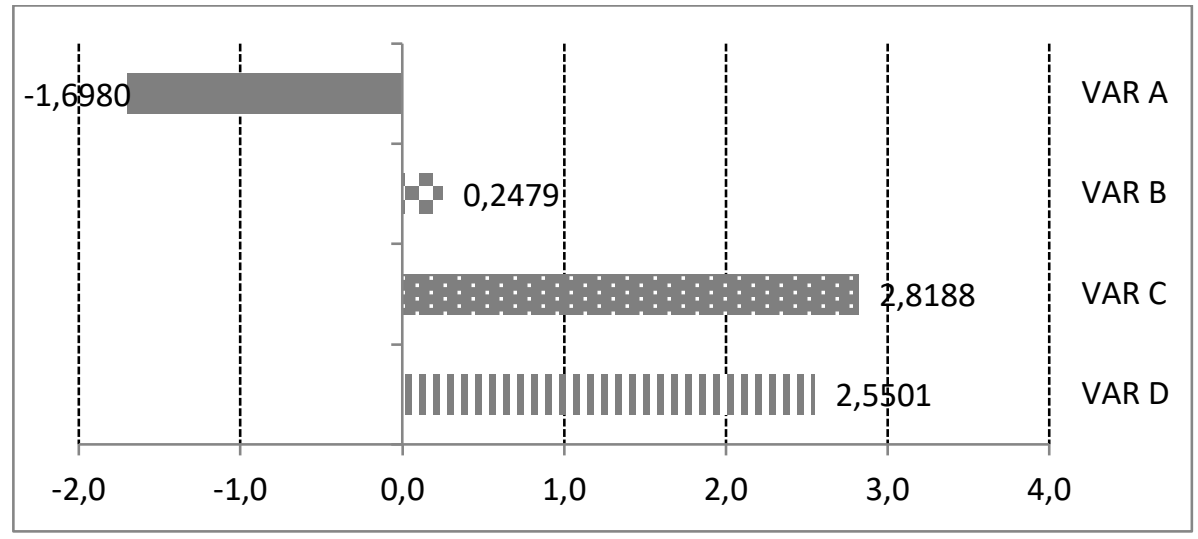

FIGURE 10.1: CAC40

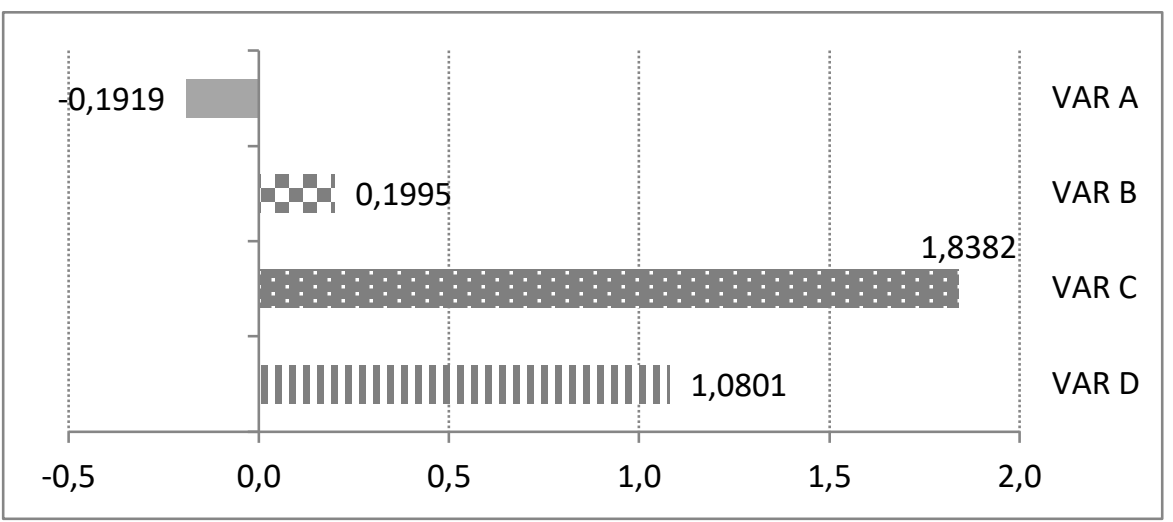

FIGURE 10.2: DAX30

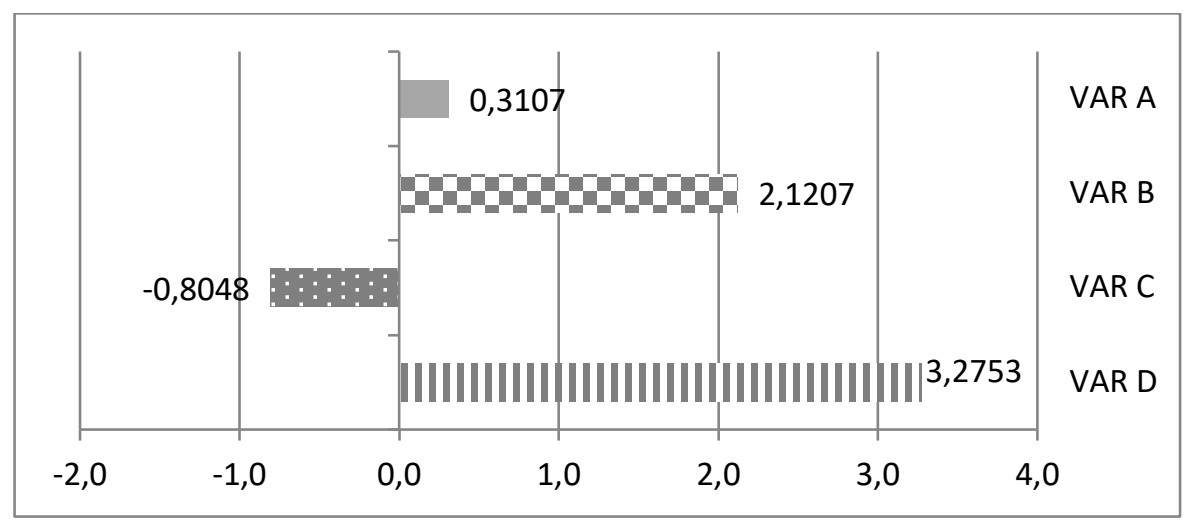

FIGURE 10.3: FTSE100

Figure 10 depicts the mean net directional spillovers from the spot to the futures market for the CAC40 (Figure 10.1), DAX30 (Figure 10.2) and FTSE100 indexes (Figure 10.3). Note that each figure presents the results of the four VAR models. When the mean has positive value (negative value) it means that the spot market is, on average, a net sender (a net receiver) of volatility spillovers. 
FIGURE 11: Persistence of models after removing microstructure noise

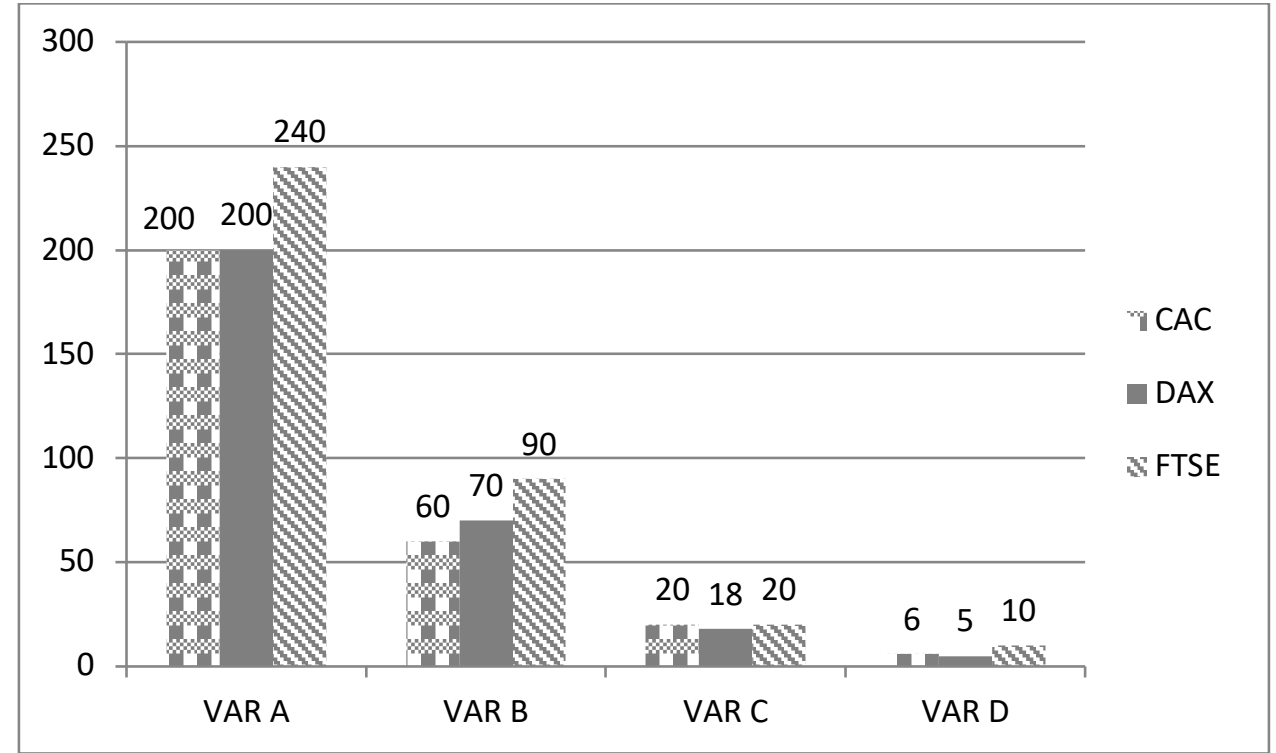

Figure 11 exhibits the persistence revealed by the IRF for each model and index, after having removed microstructure noise. The horizontal axis represents the models for each stock index, and the vertical axis shows the persistence expressed in days. Thus, from left to right, the chart represents, first those models in which intraday seasonality has not been removed (RGARCH and RV with raw returns) and then, those models that deal with the intraday periodic pattern (RGARCH and RV with standardized returns). 
FIGURE 12: Mean net directional spillover from spot to future market after removing microstructure noise.

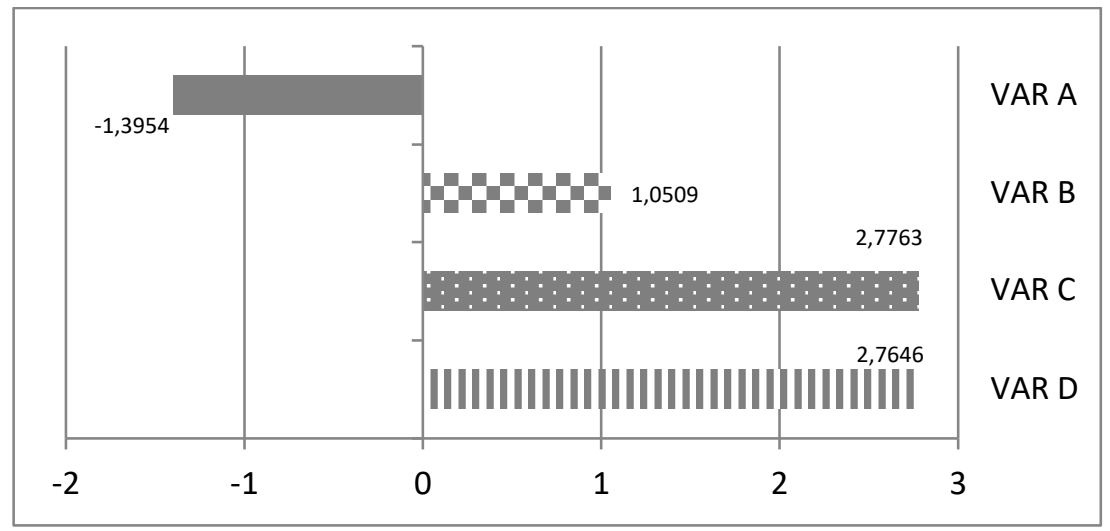

Figure 12.1: CAC40

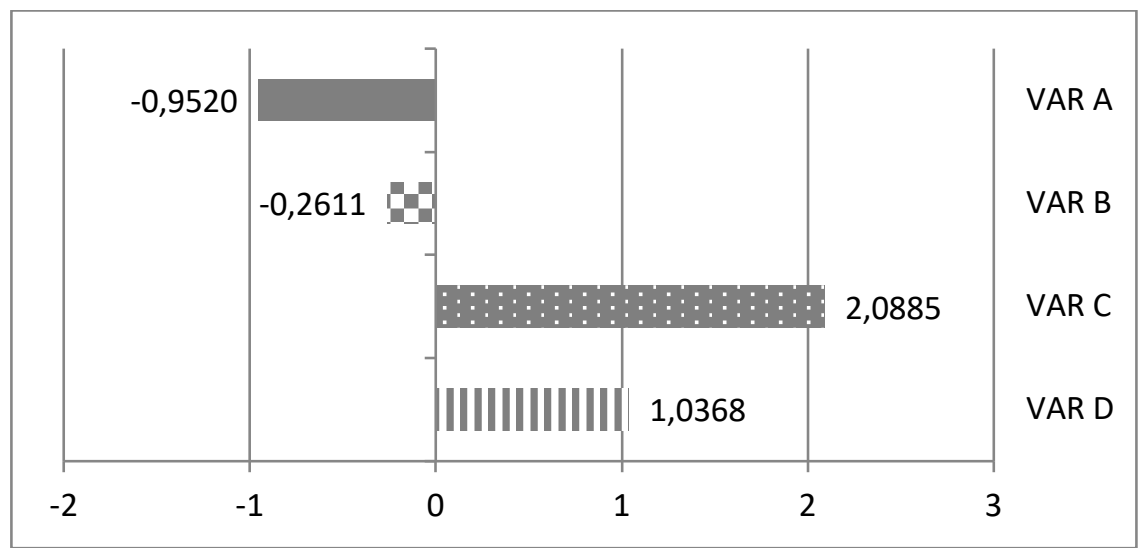

Figure 12.2: DAX30

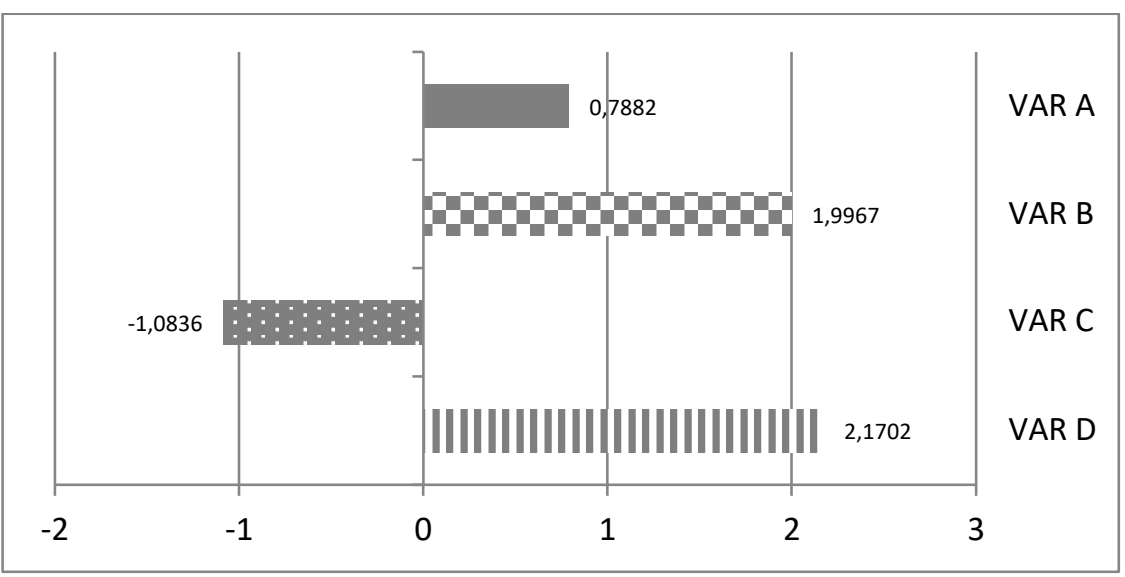

Figure 12.3: FTSE 100

Figure 12 represents the mean net directional spillovers from the spot to the futures market for the CAC40 (Figure 12.1), DAX30 (Figure 12.2) and FTSE100 indexes (Figure 12.3) after having removed microstructure noise. Note that each figure presents the results of the four VAR models. When the mean has positive value (negative value) it means that the spot market is, on average, a net sender (a net receiver) of volatility spillovers. 